Catalysis A

Manuscript Number: APCATA-D-19-00838R1

Title: Deep insight into $\mathrm{CO}$ adsorption on Ni-USY zeolite catalyst by FTIR spectroscopy. Evidence for isotopic isomerism

Article Type: VSI:BUSCA

Keywords: FTIR spectroscopy, adsorption, carbon monoxide, nickel, zeolite Corresponding Author: Professor Alexey Tsyganenko, Dr. Sci.

Corresponding Author's Institution: Saint-Petersbourg State University

First Author: Roman Belykh, Ph.D.

Order of Authors: Roman Belykh, Ph.D.; Francoise Mauge; Alexey

Tsyganenko, Dr. Sci.

Abstract: FTIR spectra of $\mathrm{CO}$ adsorbed on reduced Ni-containing USY zeolites with $\mathrm{Si} / \mathrm{Al}=30$ besides weak $\mathrm{H}$-bond with bridged hydroxyls and silanol groups and bonding to Ni2+ cations reveal formation of mono-, diand tricarbonyls with $\mathrm{Ni}+$ sites. The bands of adsorbed $\mathrm{CO}$ species are very narrow, with FWMH 1-1.5 cm-1. The spectra of isotopically mixed nickel dicarbonyl species reveal the splitting, which shows that two co molecules occupy non-equivalent positions, so that the species exist in two isomeric forms, despite the similarity of sites, following from the spectra of monocarbonyls. Possible explanations of this phenomenon are discussed. 


\section{Dear editors,}

We submit herewith the revised manuscript of our paper:

\section{Deep insight into CO adsorption on Ni-USY zeolite catalyst by FTIR spectroscopy. Evidence for isotopic isomerism.}

by

Roman A. Belykh, Francoise Mauge and A.A.Tsyganenko*

V.A.Fock Institute of Physics, St. Petersburg State University, 198504 St.Petersburg, Russia, Laboratoire Catalyse et Spectrochimie, Université de Caen Normandie, France *Corresponding author. E-mail: tsyg@ photonics.phys.spbu.ru

We tried to meet all the suggestions of the reviewers and hope to publish it in the Special Issue of the journal Applied Catalysis A: General "Surface Chemistry and Catalysis: Recent Developments in Acid-Base, Metal and Redox Catalytic Processes"

dedicated to Prof. GUIDO BUSCA on the occasion of his 65th Birthday

The Guest Editors: Gabriella Garbarino (Univ. of Genova, I)

Marco Daturi (ENSICAEN/CNRS, Caen, F)

Izabela Pieta (Polish Academy of Sciences, Warsaw, PL)

Roberto Millini (Eni S.p.A., San Donato Milanese, I)

Thank you in advance,

Yours sincerely

Alexey A. Tsyganenko 
Justification for Publication

By this we confirm that all authors listed agree to the content and publication of the submitted manuscript. The manuscript is original and was not considered for publication by any other journal.

The paper reports new data obtained by low temperature FTIR spectroscopy of CO adsorbed on Ni/USY zeolite, which is a promising catalyst for Sabatier process. The unique properties of nickel for this reaction are not understood yet, and we believe that the reported results are sufficiently new and important. In fact, the possibility of supported nickel cations to coordinate up to three molecules was observed and described earlier, but here using ${ }^{13} \mathrm{CO}$ substitution we have found that two CO in surface Ni dicarbonyl complexes are not equivalent. This newly established phenomenon, which we have called isotopic isomerism, is first reported here and seems to be rather interesting for catalysis and not only. Although the proposed explanation has to be thoroughly checked, we believe this first observation in the submitted paper makes it worth publishing in Applied Catalysis A, especially in the Special Issue.

Sincerely yours,

Alexey A.Tsyganenko 
Reply to Reviewer \#1:

The described splitting of dicarbonyl bands into 4 maxima is observed for the first time. We have added new references to the papers on $\mathrm{CO}$ adsorption on $\mathrm{Ni}$ containing zeolites, where isotopic mixtures were studied. The reported results are in agreement with our data, but the bandwidth was not small enough to see the splitting. Our data are consistent with the interpretation of a Cbonded/ O-bonded dicarbonyls, although we cannot be sure that this is the only possible explanation. Further studies are in progress.

Reply to Reviewer \#2:

We are thankful to the referee for very helpful comments. New references were added as suggested.

P 9, lines 5-6. "The band at 2172"... We agree with the reviewers doubt concerning the assignment of this band to residual $\mathrm{Na}$ + ions. We suggest now another explanation. However, the attribution of this band is not important for the paper.

Fig 3 caption is corrected: spectra 1 and 3 were mixed up.

$P$ 10. The caption of Fig. 8 is corrected.

P 11, lines 19-20. "We cannot say yet firmly what is the origin of their difference..." we tried to explain it better in the following sentences (see the text).

$P$ 12. We have not found any temperature dependence of relative intensities of the dicarbonyl bands. The distinct bands of such dimers cannot be assigned to separate molecules, but rather to symmetric and antisymmetric vibrations of the complex. Thus, it is not possible yet to discuss the relative proportion of $\mathrm{C}$-bonded and O-bonded species basing on our up-to-date results.

Reply to Reviewer \#3:

Some improvements of the language are done, misprints corrected. We add the figures of better quality in separate files. 


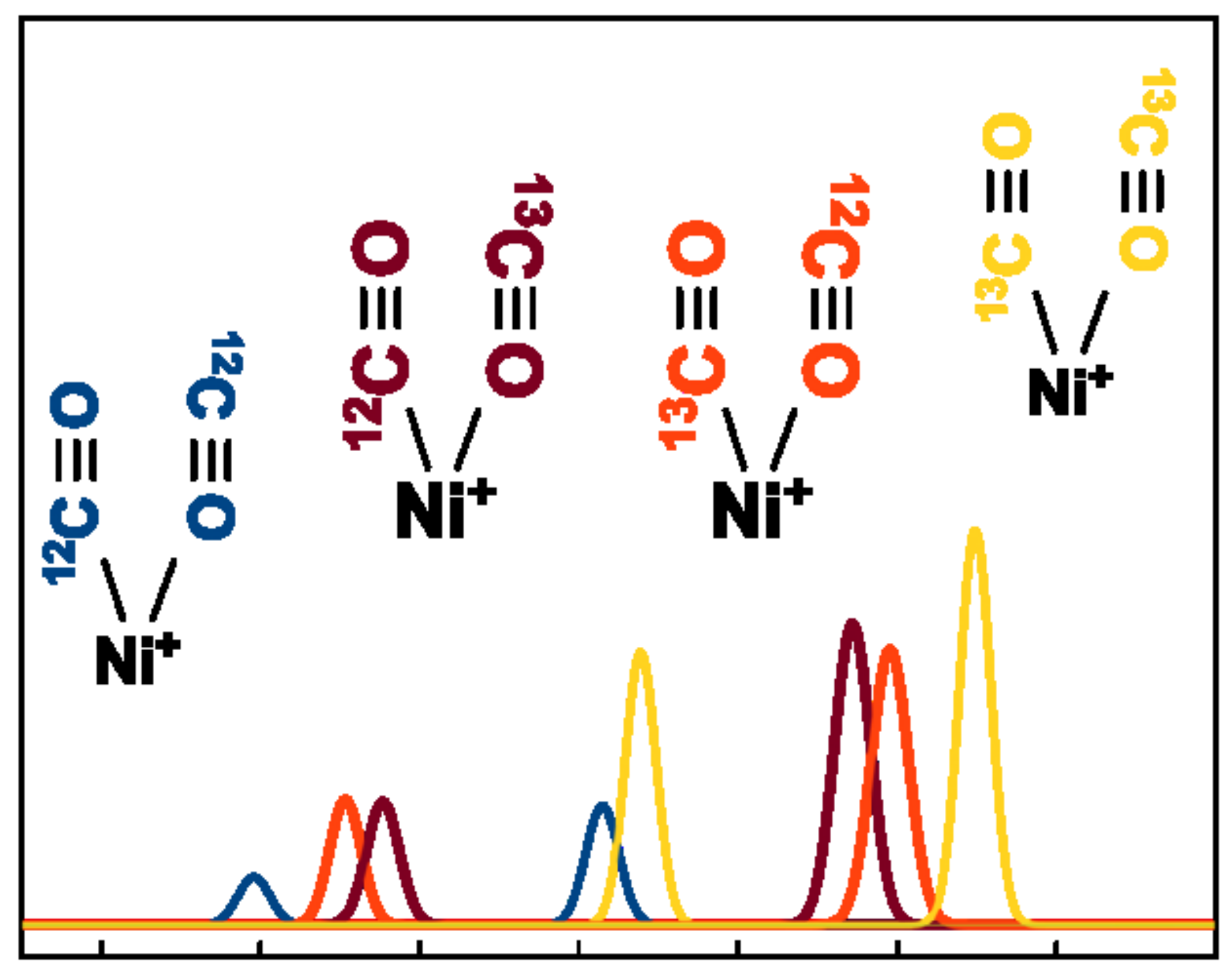




\section{${ }^{*}$ Highlights}

Bands in FTIR spectra of CO adsorbed on reduced Ni-USY zeolite are extremely narrow Spectra of nickel mono-, di-, and tricarbonyl species can be identified on desorption Spectra of isotopic mixtures show that CO molecules in dicarbonyls are not equivalent A model illustrating thus established phenomenon of isotopic isomerism is proposed 


\title{
Deep insight into CO adsorption on Ni-USY zeolite catalyst by FTIR spectroscopy. Evidence for isotopic isomerism
}

\author{
R.Belykh ${ }^{1}$, F.Mauge ${ }^{2}$, A.Tsyganenko ${ }^{1}$ \\ ${ }^{1}$ V. A. Fock Institute of Physics, St. Petersburg State University, St. Petersburg, 198504, Russia, \\ ${ }^{2}$ Laboratoire Catalyse et Spectrochimie, ENSICAEN - Université de Caen Normandie - CNRS, 6 \\ Boulevard du Maréchal Juin, 14050 Caen Cedex, France
}

\begin{abstract}
FTIR spectra of $\mathrm{CO}$ adsorbed on reduced $\mathrm{Ni}$-containing USY zeolites with $\mathrm{Si} / \mathrm{Al}=30$ besides weak $\mathrm{H}$ bond with bridged hydroxyls and silanol groups and bonding to $\mathrm{Ni}^{2+}$ cations reveal formation of mono-, di- and tricarbonyls with $\mathrm{Ni}^{+}$sites. The bands of adsorbed $\mathrm{CO}$ species are very narrow, with FWMH $1-1.5 \mathrm{~cm}^{-1}$. The spectra of isotopically mixed nickel dicarbonyl species reveal the splitting, which shows that two CO molecules occupy non-equivalent positions, so that the species exist in two isomeric forms, despite the similarity of sites, following from the spectra of monocarbonyls. Possible explanations of this phenomenon are discussed.
\end{abstract}

\section{Introduction}

The Sabatier reaction of $\mathrm{CO}_{2}$ hydrogenation gets into public attention as a method to produce methane from renewable energy sources. It was even mentioned in ambitious projects for interplanetary spaceflights. The reaction requires $\mathrm{CO}_{2}, \mathrm{H}_{2}$ and an active catalyst. The catalysts for Sabatier process usually consist of oxide support and transition metal, almost always nickel, although both parts can be varied.[1]

We have focused our research on zeolite-based $\mathrm{Ni}$ catalysts, for they show high conversion and selectivity [2] while the materials are relatively cheap. However, is not clear yet, which characteristics of nickel account for its specific catalytic properties.

IR spectroscopy was used as the main method in this study, since it provides detailed information about surface complexes of adsorbed molecules [3],[4], and is successfully applied in operando catalytic studies. IR spectra of $\mathrm{CO}$ adsorbed on HY zeolites are thoroughly studied [5],[6]. Spectra of $\mathrm{CO}$ adsorbed on $\mathrm{Ni}$-impregnated zeolites were also investigated, and the results show high sensitivity to the charge of $\mathrm{Ni}$ ions.

Other methods show that $\mathrm{Ni}$ state in zeolites is not strictly determined [7]. Impregnated $\mathrm{Ni}^{2+}$ ions upon dehydration populate hexagonal prisms [8]. Maximum population is 12 ions per unit cell, and when the loading exceeds this value the increase in metallic $\mathrm{Ni}^{0}$ concentration should be expected. NMR data [9] infer that $\mathrm{Ni}^{2+}$ ions in $\mathrm{Y}$ zeolites can move outside hexagonal prism to sodalite cages at $673 \mathrm{~K}$. The process is reversible and depends on the amount of water present. Some Ni ions stay in exchange positions, with 2+ charge, others stick together, possibly keeping charge disbalance, creating unusual weakly-charged surfaces. $\mathrm{Ni}^{+}$sites in Ni-ZSM-5 are stable up to 
moderately high temperatures $(550-600 \mathrm{~K})$. At higher temperatures, the $\mathrm{Ni}^{+}$sites are converted to $\mathrm{Ni}^{0}$ and $\mathrm{Ni}^{2+}$ in the disproportionation reaction. [7]

In this study we have investigated the properties of $\mathrm{Ni}$ centres with $\mathrm{CO}$ as a probe molecule. Comparatively narrow bands in the spectra of $\mathrm{Y}$ zeolites with high Si/Al ratios facilitate application of isotopic substitution for establishing the structure of surface species.

\section{Experimental}

Ultrastable Y-zeolite (USY) in $\mathrm{H}$ form with $\mathrm{Si} / \mathrm{Al}$ ratio of 30 was purchased from Zeolyst (CBV760). Ni was introduced by incipient wet impregnation. Water solution of $\mathrm{Ni}\left(\mathrm{NO}_{3}\right)_{2} \cdot 6 \mathrm{H}_{2} \mathrm{O}$, (chem. pure) was prepared in quantity close to total pore volume of the zeolite in a portion and with proper concentration to get 10 (denoted below as $\mathrm{Ni10}$ ) or 14 ( $\mathrm{Ni14}$ ) weight percent loading of $\mathrm{Ni}$. The solution was added dropwise to zeolite dried at $353 \mathrm{~K}$ overnight, under constant stirring in mortar. When all the solution added, the sample was a homogeneous heavy powder of light-green color. After impregnation the catalyst was dried at $413 \mathrm{~K}$ at least for two hours and calcined at $773 \mathrm{~K}$ under air flow for 5 hours. The temperature changing rate was around $5 \mathrm{~K} / \mathrm{min}$. After calcination the colour of the sample becomes light-grey.

For spectral studies batches of powder were pressed into self-supported pellets in a form of disks, roughly $15 \mathrm{mg}$ per $2.0 \mathrm{~cm}^{2}$. Then a rectangle was cut from the disk, to fit in the homemade sample-holder. The sample was inserted into the low-temperature IR cell described elsewhere [10] and activated in-situ. The samples were heated at $413 \mathrm{~K}$ for two hours under constant pumping by a turbomolecular pump, and then the temperature was increased up to $723 \mathrm{~K}$ at the rate of $5 \mathrm{~K} / \mathrm{min}$.

For Ni loaded samples, $\mathrm{H}_{2}$ was introduced at $\mathrm{T}=723 \mathrm{~K}$, up to the pressure of about 40 Torr in the sample volume. The sample volume was connected to a trap cooled with liquid nitrogen, so that water formed during the reduction would be frozen there. After 30 minutes the rest of $\mathrm{H}_{2}$ was removed by pumping and another portion of $\mathrm{H}_{2}$ was introduced. The activated sample was slowly cooled down to $77 \mathrm{~K}$ in the low part of the cell, about 0,5 Torr of He was introduced in the sample volume in order to improve thermal contact of the sample with the cold cell walls, and the reference spectrum of the clean sample was recorded. Afterwards it could be subtracted from the spectra with adsorbed CO.

$\mathrm{CO}$ gas of chemical purity or its mixture with ${ }^{13} \mathrm{CO}$ was introduced through a trap cooled by liquid nitrogen into sample volume of the cell kept at $77 \mathrm{~K}$ by several portions, until the saturation of surface sites was reached at equilibrium $\mathrm{CO}$ pressure of $1-5$ Torr. Then $\mathrm{CO}$ was removed by pumping for certain time, followed by re-filling the cell by a new portion of He. The procedure was repeated several times, first with the sample in the cooled part of the cell, then it was moved up into the quartz tube for evacuation at $300 \mathrm{~K}$ or at elevated temperature, if needed. At every stage of adsorption or desorption spectra were recorded with the typical resolution of $2 \mathrm{~cm}^{-1}$, sometimes even $1 \mathrm{~cm}^{-1}$ to estimate the width of narrow bands.

Inductively Coupled Plasma Mass Spectrometry analysis for $\mathrm{Si}, \mathrm{Al}, \mathrm{Na}, \mathrm{Ni}$ concentration provided the data on Ni loading, which turned to be 10.2 and 13,7 weight percent for Ni10/H-USY and Ni14/H-USY, respectively, close enough to the desired values of 10 or $14 \%$ of the metal. 


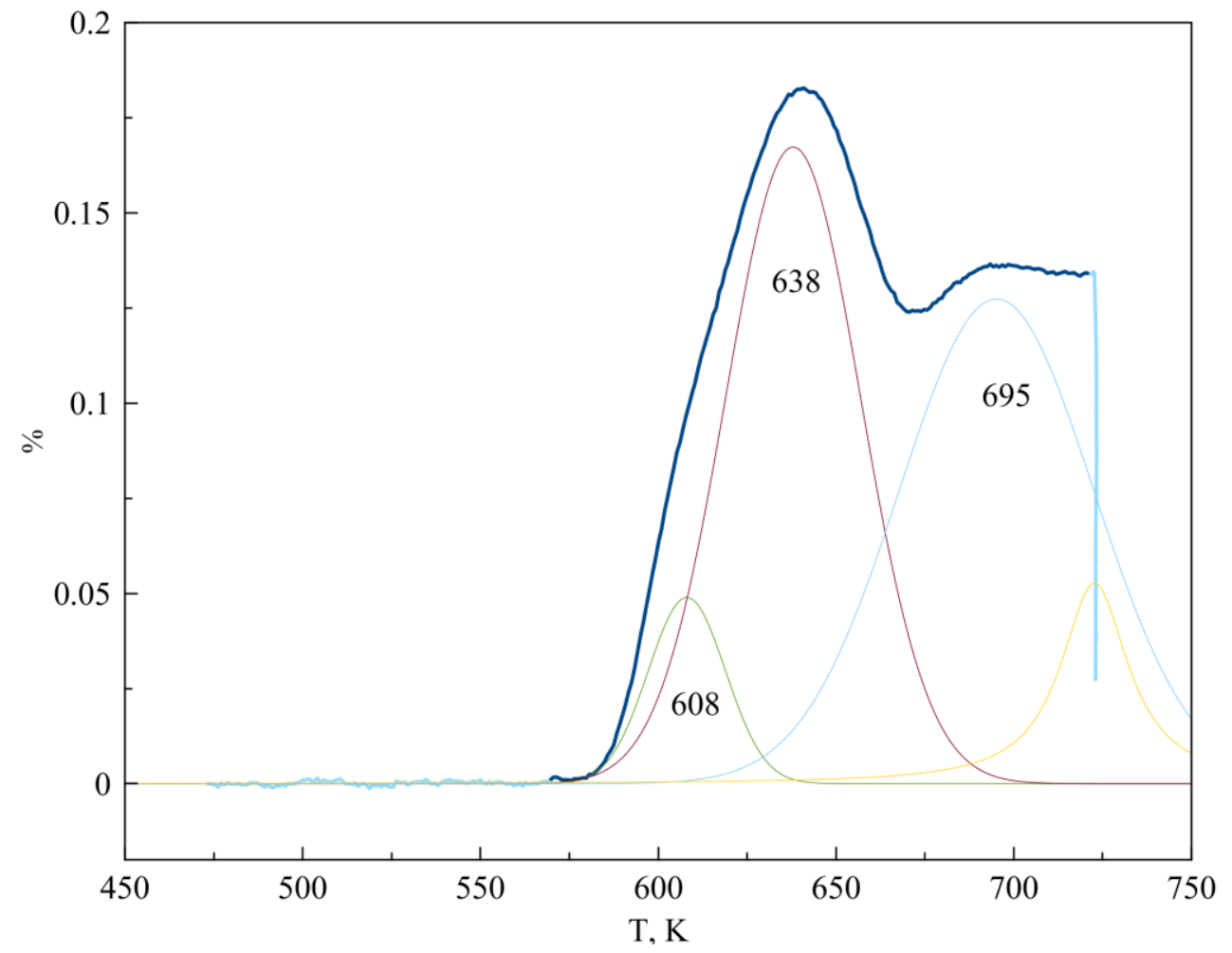

Figure 1 Temperature Programmed Reduction curve for Ni10/H-USY sample.

TPR experiments show (Figure 1) three maxima of reduction on heating up to $723 \mathrm{~K}$ in $75 \% \mathrm{Ar}$ $25 \% \mathrm{H}_{2}$ flow at temperatures 608,638 and $695 \mathrm{~K}$. Taking into account that pure Ni oxides are reduced in one-step process at distinct temperatures: $611 \mathrm{~K}$ for $\mathrm{Ni}_{2} \mathrm{O}_{3}$ and $678 \mathrm{~K}$ for $\mathrm{NiO}$ [11], we assume that the shoulder at $608 \mathrm{~K}$ corresponds to small amount of $\mathrm{Ni}^{3+}$, while maxima at 638 and $695 \mathrm{~K}$ are due to transformations of $\mathrm{Ni}^{2+}$ to $\mathrm{Ni}^{+}$and further reduction to $\mathrm{Ni}^{0}$ metal. These reduction temperatures are lower than given in literature for pure Ni oxides. 


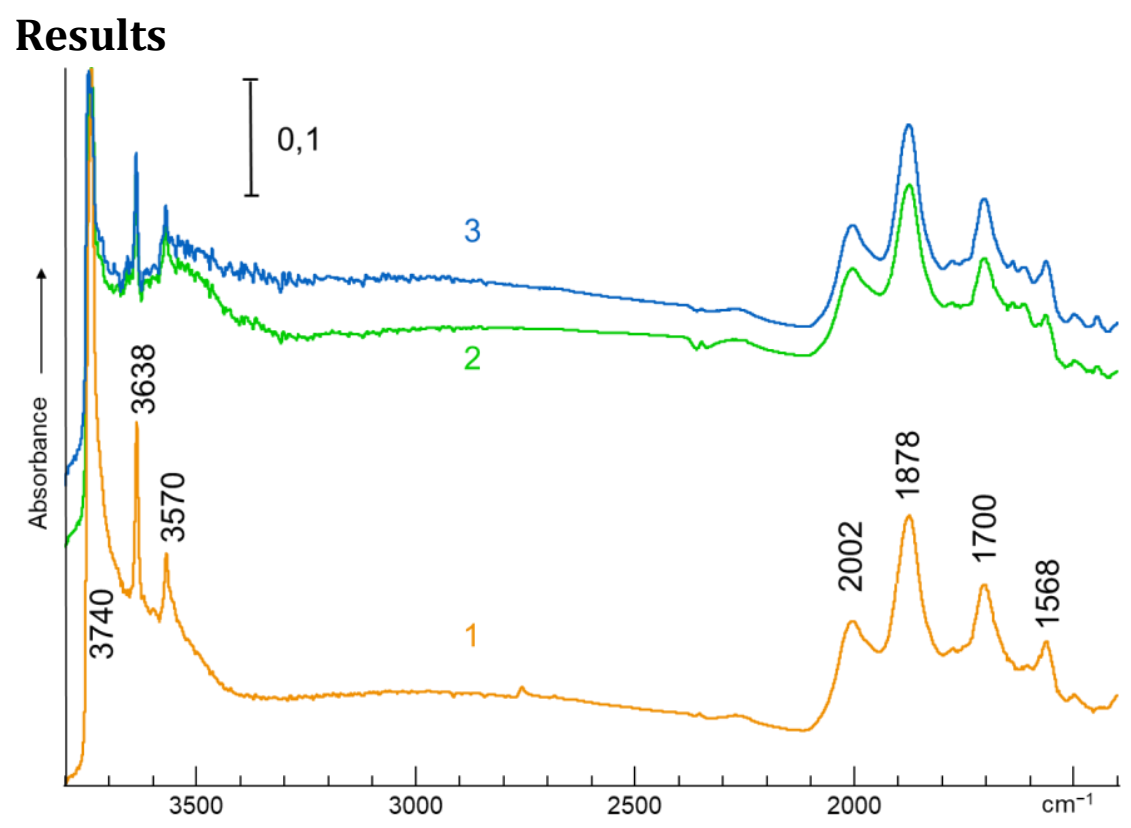

Figure 2. IR spectra of USY samples with $\mathrm{O}(1), 10$ (2) and 14 (3) weight percent of $\mathrm{Ni}$, activated at $723 \mathrm{~K}$ and registered at $77 \mathrm{~K}$.

The spectra of activated support zeolite and metal-loaded samples are shown in Figure 2. In the $\mathrm{OH}$ stretching region one can see the band at 3738 , which at $77 \mathrm{~K}$ reveals a structure of three maxima at 3747,3740 and $3735 \mathrm{~cm}^{-1}$, at 3638 and $3570 \mathrm{~cm}^{-1}$ attributed to silanol, supercage and sodalite cage $\mathrm{OH}$ groups, respectively [6]. Bands at $2002 \mathrm{~cm}^{-1}$ and below are due to zeolite framework vibrations. Even if the spectra are normalized to the same intensity of the framework bands, we can state that the introduction of $\mathrm{Ni}$ leads to the decreased intensities of $\mathrm{OH}$ groups with the possible exception of that one at $3570 \mathrm{~cm}^{-1}$.

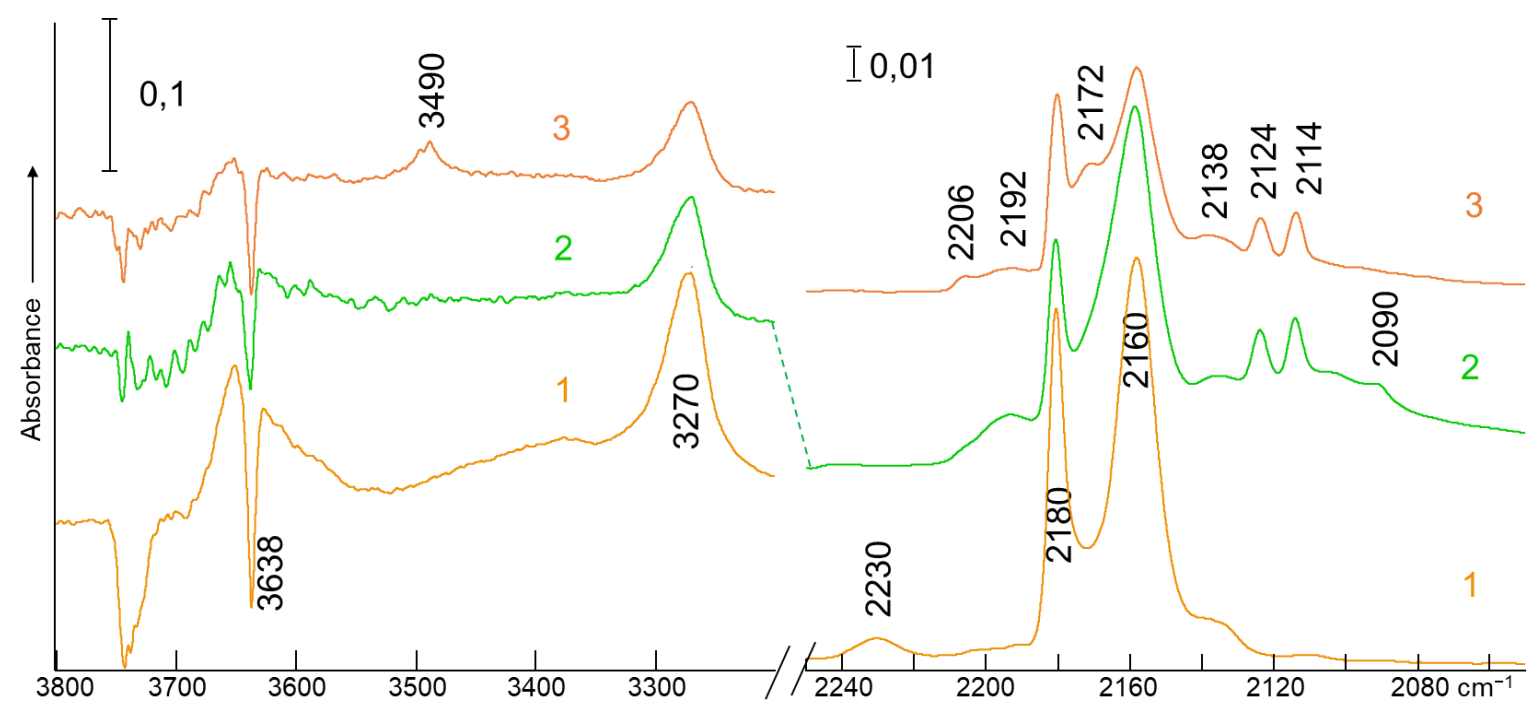

Figure 3. FTIR spectra of ${ }^{12} \mathrm{CO}$ adsorbed on H-USY (1), Ni10/H-USY (2) and Ni14/H-USY (3) at $77 \mathrm{~K}$ with 0.2 Torr He in the cell. The spectrum of the sample before adsorption is subtracted.

Addition of the first doses of $\mathrm{CO}$ to all the three studied samples in the cell, preliminary cooled with liquid nitrogen (Figure 3), results in the intensity decrease of the $\mathrm{OH}$ band at 3638 with simultaneous growth of the band of perturbed hydroxyls at $3270 \mathrm{~cm}^{-1}$ and a band of adsorbed ${ }^{12} \mathrm{CO}$ 
at $2180 \mathrm{~cm}^{-1}$. If the pressure of $\mathrm{CO}$ in the cell increases up to $1-5$ Torr an intense band at $2158 \mathrm{~cm}^{-1}$ grows simultaneously with the band at about $3650 \mathrm{~cm}^{-1}$ and the decrease of silanol band at $c a$ $3740 \mathrm{~cm}^{-1}$. One more band at $2138 \mathrm{~cm}^{-1}$ increases in intensity and moves to $2140 \mathrm{~cm}^{-1}$ with the growing coverage.

Other bands are not the same for different samples, as can be seen from Figure 3. A weak band at $2230 \mathrm{~cm}^{-1}$ arises in the spectrum of H-USY zeolite. In the spectra of Ni-loaded samples along with the bands of $\mathrm{CO}$ adsorbed on hydroxyl groups one can see a couple of bands at 2206 and $2192 \mathrm{~cm}^{-1}$ and a pair of very narrow $\left(\Delta \mathrm{v}_{1 / 2}<1.5 \mathrm{~cm}^{-1}\right)$ bands at 2124 and $2114 \mathrm{~cm}^{-1}$. A band at $2172 \mathrm{~cm}^{-1}$ is more prominent in the spectrum of Ni14/H-USY sample. It is present but rather weak for Ni10/H-USY sample, and absent for H-USY. It is accompanied by a slight change in the shape and position of the $3490 \mathrm{~cm}^{-1}$ band.

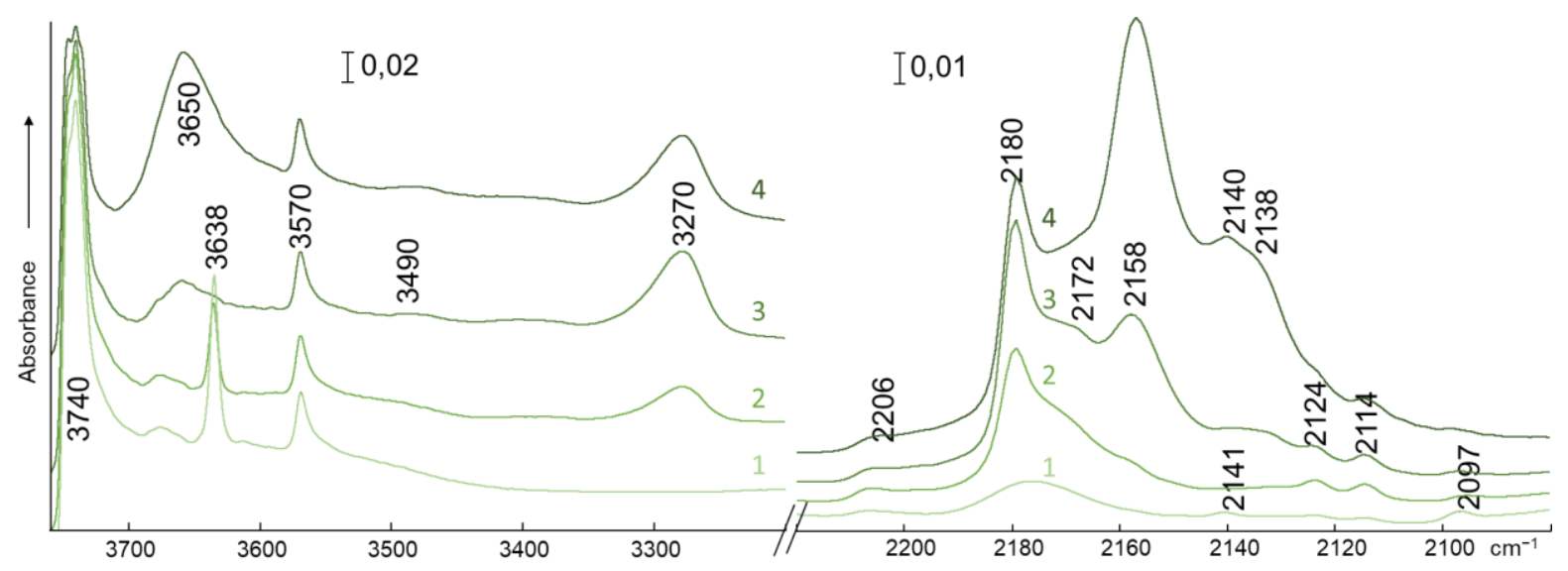

Figure 4. FTIR spectra of CO adsorbed on Ni14/H-USY by small doses admission. Coverage increases from 1 to 4 while the equilibrium pressure grows up to 1,48 Torr at $77 \mathrm{~K}$.

The process of $\mathrm{CO}$ gradual adsorption is illustrated in Figure 4. As there was no He in the cell in this experiment, the initial sample temperature was higher than $77 \mathrm{~K}$. The resulting picture is identical to that at the beginning of desorption process after full saturation of the surface.

The first to appear are the bands at 2180 and $3270 \mathrm{~cm}^{-1}$ accompanied by intensity decrease of the $3638 \mathrm{~cm}^{-1}$ band. The pair of weak bands at 2141 and $2097 \mathrm{~cm}^{-1}$ at curve 1 is replaced by those at 2124 and $2114 \mathrm{~cm}^{-1}$ (Figure 4 curve 2). The $2180 \mathrm{~cm}^{-1}$ band reaches its maximum intensity when the $3638 \mathrm{~cm}^{-1}$ band is completely gone (Figure 4 curve 3 ). The intensity of the band at $2172 \mathrm{~cm}^{-1}$ increases together with that at $3490 \mathrm{~cm}^{-1}$. The appearance of $2158 \mathrm{~cm}^{-1}$ band is accompanied by the growth of that at $3650 \mathrm{~cm}^{-1}$ and decrease of silanol band at $3740 \mathrm{~cm}^{-1}$. The last to appear are poorly resolved broad bands at $2140-2138 \mathrm{~cm}^{-1}$, they increase with the growing pressure of CO gas in the cell up to several Torr.

CO desorption is illustrated in Figure 5. As soon as the broad band at $2158 \mathrm{~cm}^{-1}$ is removed, much weaker narrow band at exactly the same position of maximum becomes visible. It disappears together with the bands at 2124 and $2114 \mathrm{~cm}^{-1}$ after prolonged evacuation of the cold cell when other bands of adsorbed $\mathrm{CO}$ are gone (Figure 5 curve 2) and the spectrum of surface $\mathrm{OH}$ groups is restored completely. Simultaneously, a new pair of narrow bands arises at 2141 and $2097 \mathrm{~cm}^{-1}$. 
Evacuation at $300 \mathrm{~K}$ leads to simultaneous disappearance of that pair while a new band appears at $2018 \mathrm{~cm}^{-1}$. This band resists pumping at $373 \mathrm{~K}$, but disappears after heating in vacuum at $473 \mathrm{~K}$.

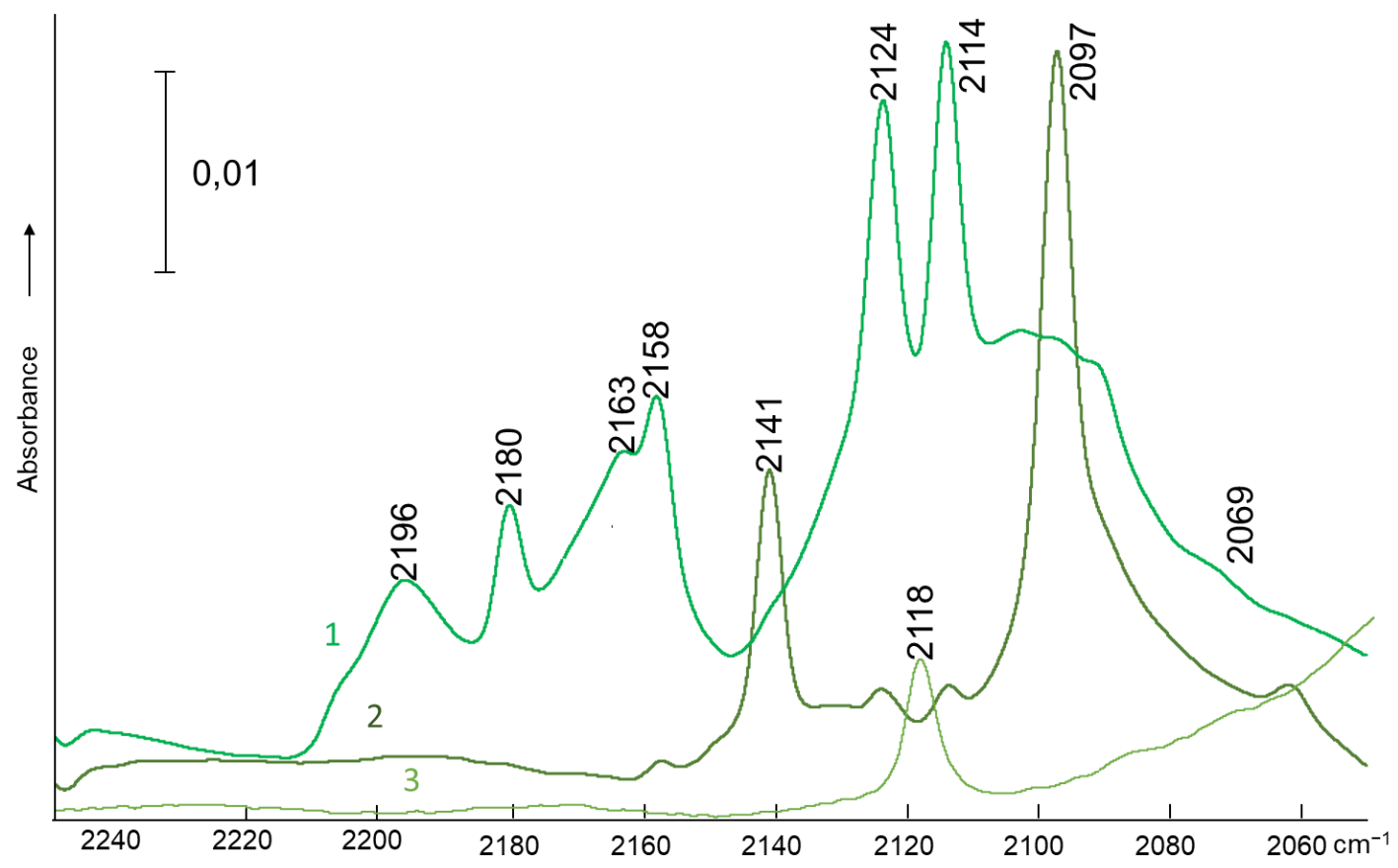

Figure 5. Spectra of ${ }^{12} \mathrm{CO}$ adsorbed on Ni10/H-USY at $77 \mathrm{~K}$, with 0.2 Torr of He present. Coverage decreases from top to bottom. 1 - pumped for 3 minutes, 2 - pumped for 10 minutes, 3 - pumped at room temperature for 10 minutes.

In order to clarify the interpretation of the results, the experiments with the mixtures of ${ }^{12} \mathrm{CO}$ and ${ }^{13} \mathrm{CO}$ were performed. Figure 6 shows the evolution of spectrum of such a mixture with about $70 \%$ of ${ }^{13} \mathrm{CO}$ on desorption. As shows the comparison of curves shown in this figure with the spectra of pure ${ }^{12} \mathrm{CO}$ from Figure 5, all the bands of ${ }^{12} \mathrm{CO}$ above $2158 \mathrm{~cm}^{-1}$ have their analogs simply shifted to the lower wavenumbers by about $49 \mathrm{~cm}^{-1}$. So, the band at 2180 and the broad one $2158 \mathrm{~cm}^{-1}$ are shifted to 2131 and $2109 \mathrm{~cm}^{-1}$, respectively. The sharp band of ${ }^{12} \mathrm{CO}$ at $2158 \mathrm{~cm}^{-1}$ is merged with the shifted analogs of absorption at 2206-2192 $\mathrm{cm}^{-1}$. The most stable band at $2018 \mathrm{~cm}^{-1}$ has its ${ }^{13} \mathrm{CO}$ analog at $2069 \mathrm{~cm}^{-1}$. Other weak bands observed below $2158 \mathrm{~cm}^{-1}$ produce more complicated picture in the spectrum of mixed isotopes. 


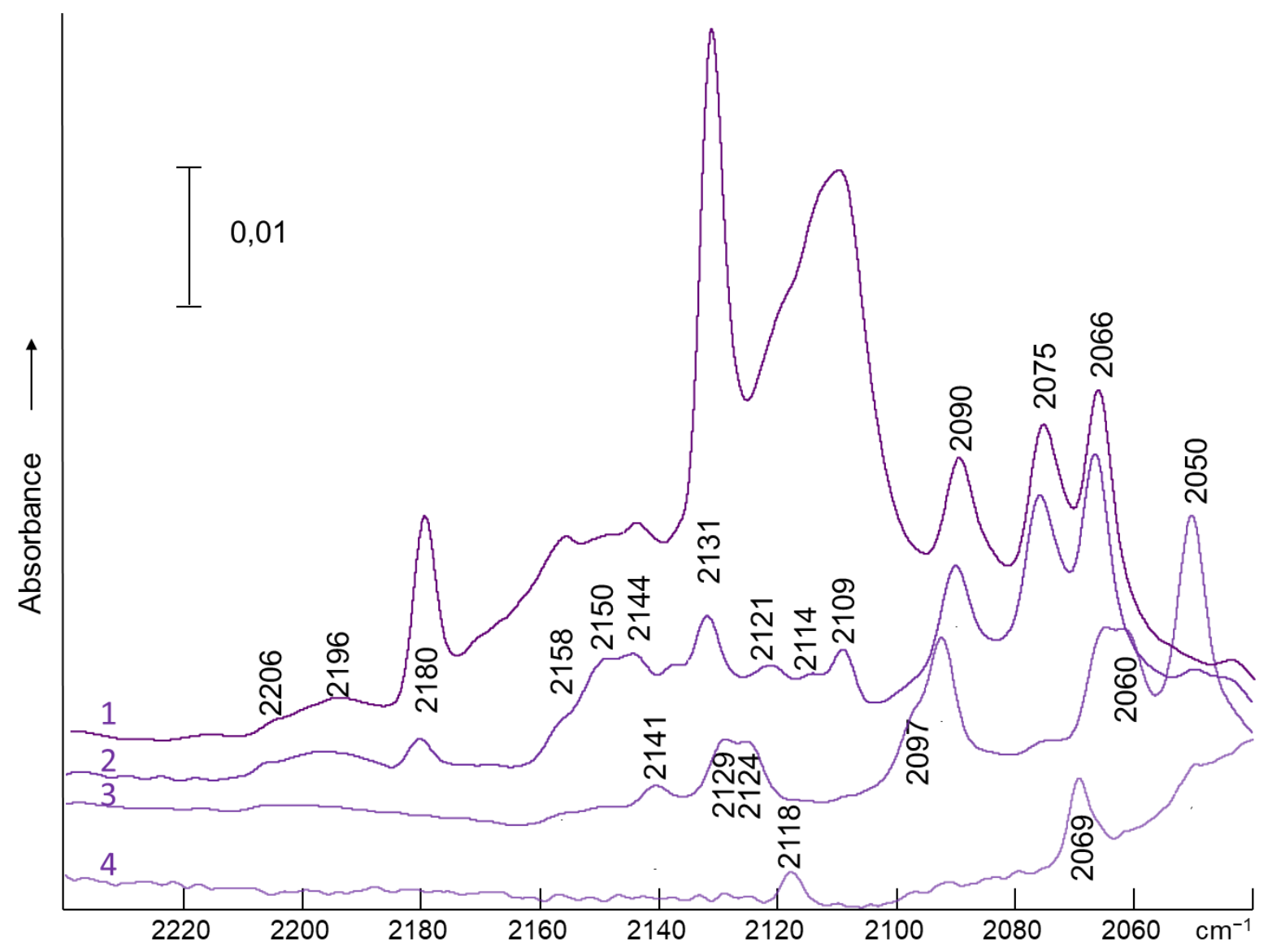

Figure 6. FTIR spectra of $28 \%{ }^{12} \mathrm{CO}+72 \%{ }^{13} \mathrm{CO}$ mixture desorbed from Ni10/H-USY. CO is pumped by turbomolecular pump for successively increased time at $77 \mathrm{~K}(1-3)$ and $300 \mathrm{~K}(4)$.

A pair of bands at 2141 and $2097 \mathrm{~cm}^{-1}$ have their ${ }^{13} \mathrm{CO}$ analogs at 2092 and $2050 \mathrm{~cm}^{-1}$, but simultaneously, at the conditions when no other bands are seen in the spectrum of pure ${ }^{12} \mathrm{CO}$, two close doublets are seen at $2129-2124$ and $2164-2160 \mathrm{~cm}^{-1}$. Even more complex spectrum arises before, when the weakly bound molecules are just removed, the bands of surface $\mathrm{OH}$ groups are mostly recovered, and the remaining ${ }^{12} \mathrm{CO}$ accounts for the pair of bands at 2124 and $2114 \mathrm{~cm}^{-1}$ and one more sharp band at $2158 \mathrm{~cm}^{-1}$. In attempt to assign the observed bands in this case we have run the spectra of mixtures of different enrichment, which have about 30 and $50 \%$ of ${ }^{13} \mathrm{CO}$. The results are shown in Fig. 7. Subtracting the spectrum of pure ${ }^{12} \mathrm{CO}$ from those of mixtures, we were able to obtain the spectrum of mixed isotopic species. The latter was subtracted from that of $70 \%{ }^{13} \mathrm{CO}$ with thus chosen factor that almost only the triplet of bands due to pure ${ }^{13} \mathrm{CO}$ species could be seen at 2109, 2075 and $2065 \mathrm{~cm}^{-1}$, exactly at the positions expected for the positions of completely substituted species if we shift the frequencies of corresponding ${ }^{12} \mathrm{CO}$ species down by $49 \mathrm{~cm}^{-1}$. Now, if we subtract this spectrum from that of a mixture with $50 \%$ enrichment, we obtain a spectrum of partly substituted species, shown in Figure 7 together with the spectra of pure ${ }^{12} \mathrm{CO}$ and ${ }^{13} \mathrm{CO}$ species, existing at this stage of $\mathrm{CO}$ desorption. The resulting spectrum displays at least 6 distinct bands whose position with the proposed assignment are shown below in Table 1. An extra band at about $2090 \mathrm{~cm}^{-1}$, which is present in curves 1 and 3, does not correlate with others and can be presumably assigned to $\mathrm{CO}$ adsorbed on $\mathrm{Ni}^{0}$. 


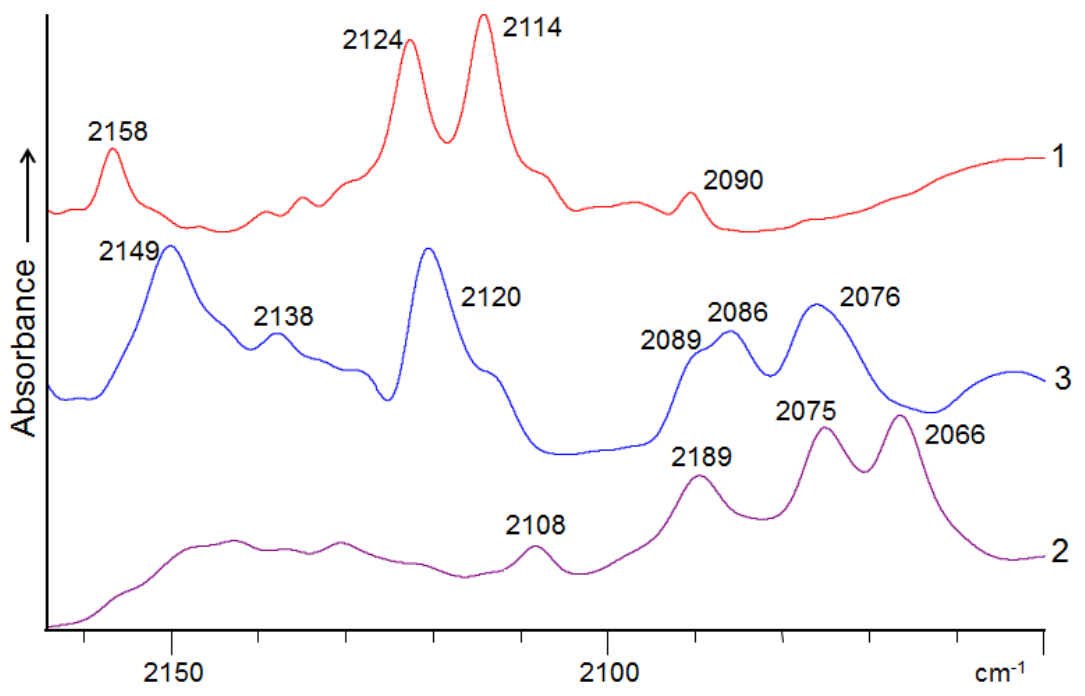

Figure 7. FTIR spectra of Ni tricarbonyl surface species of different isotopic compositions. $1-99 \%$ of ${ }^{12} \mathrm{CO}$, 2 - almost pure ${ }^{13} \mathrm{CO}$ obtained from $28 \%{ }^{12} \mathrm{CO}+72 \%{ }^{13} \mathrm{CO}$ mixture by subtraction of the spectrum of that of $\mathrm{ca} 50: 50 \%$; 3 - spectrum of $60 \%{ }^{12} \mathrm{CO}+40 \%{ }^{13} \mathrm{CO}$ mixture after subtraction of curves 1 and 2 .

\section{Discussion}

The observed spectrum of HUSY zeolite as well as of $\mathrm{CO}$ adsorbed on the $\mathrm{OH}$ groups of the studied samples are in agreement with the published data. The great $\mathrm{VOH}$ frequency shift $\left(\Delta \mathrm{vOH}=360 \mathrm{~cm}^{-1}\right)$ as well as the high position of the corresponding $\mathrm{vCO}$ band $\left(2180 \mathrm{~cm}^{-1}\right)$ testify for a high acidity of the hydroxyls, close to the highest values observed for zeolites [12]. Comparatively small width of the bands of $\mathrm{H}$-bonded $\mathrm{OH}$-groups, apparently, is due to homogeneity of the hydroxyl groups in their properties, typical of $\mathrm{Y}$ zeolites with high Si/Al ratio.

Unlike the latter band of zeolitic bridged $\mathrm{OH}$ groups, the band of silanol groups is broad and has the structure of several maxima. Apparently, these groups have different environment. Some of them can be located at exterior surface of microcrystals, others could be in the defects of inner surface. Their properties should be not the same, and it is not by chance that the band of CO bound to these groups is also broad and its band moves on desorption from 2158 to $2163 \mathrm{~cm}^{-1}$, where it can be seen in Figure 4.

The band at $2138-2140 \mathrm{~cm}^{-1}$ which appear at high coverages is usually considered as physisorption or liquid-like species, but the high enthalpy of adsorption $(11 \mathrm{~kJ} / \mathrm{mol}$ for silica against $6.044 \mathrm{~kJ} / \mathrm{mol}$ for condensation), and the downward frequency shift by $5-7 \mathrm{~cm}^{-1}$, not observed for liquid or dissolved CO infer that it is rather due to the side-on complexes with siloxane bridges [13]. Certain contribution to the intensity of the band at $2138 \mathrm{~cm}^{-1}$ make $\mathrm{CO}$ molecules bound to silanol groups via oxygen atom [14].

The band at $2230 \mathrm{~cm}^{-1}$, seen in the spectra of H-USY zeolites can be due to $\mathrm{CO}$ adsorbed on extraframework or even framework $\mathrm{Al}^{3+}$ ions from the supercage side [15]. In our case its appearance can mean that the sample was somehow damaged during the activation procedure if the pumping was not efficient enough to avoid hydrotreatment. 
The weak bands at 2206, and $2196-2192 \mathrm{~cm}^{-1}$ are assigned to $\mathrm{CO}$ adsorbed on $\mathrm{Ni}^{2+}$ ions [5]. These bands have different relative intensities in 10 and $14 \%$ loaded samples. This can be considered as an evidence for different positions of these ions in the structure of zeolite.

The band at $2172 \mathrm{~cm}^{-1}$, visible in the spectrum of Ni14/H-USY sample (Figure 3), is less distinctive for $\mathrm{Ni10} / \mathrm{H}$-USY and seems absent for H-USY. As soon as its intensity correlates with that of the $3490 \mathrm{~cm}^{-1}$ band and is accompanied by the weak perturbation of the band at $3570 \mathrm{~cm}^{-1}$, it could be tentatively assigned to $\mathrm{CO}$ interaction with sodalite cage $\mathrm{OH}$ groups. Such possibility can be somehow stimulated by nickel ions, which, according to [16], can be bound to sodalite cage oxygen atoms.

$\mathrm{Ni}$ impregnation, apparently, blocks certain part of surface $\mathrm{OH}$ groups, this explains the intensity decrease of the $\mathrm{OH}$ bands in Figure 2. The bands of adsorbed $\mathrm{CO}$ at $2158 \mathrm{~cm}^{-1}$ and below in the spectra of Ni-loaded samples in agreement with earlier studies [17], should be assigned to molecules bound to $\mathrm{Ni}^{+}$ions. Appearance of new bands on desorption is a typical manifestation of lateral interactions between the adsorbed molecules, and sequential observation of three, two and, finally one band should be associated with adsorption of three, two or one molecule at the same site. The method of isotopic dilution or substitution provides more information about the nature of interaction and the arrangement of the interacting molecules.

Isotopic experiments with ${ }^{13} \mathrm{CO}$ provide new detail on the $\mathrm{Ni}$ centers in the system. The last $\mathrm{CO}$ band remaining at $2018 \mathrm{~cm}^{-1}$ after desorption even at elevated temperatures in the spectra registered at $77 \mathrm{~K}\left(2014 \mathrm{~cm}^{-1}\right.$ at $\left.300 \mathrm{~K}\right)$ has its ${ }^{13} \mathrm{CO}$ analog at $2069 \mathrm{~cm}^{-1}$. The ratio of frequencies measured with high accuracy from the same spectrum gives a value of isotopic factor 1.0235 . This is a little bit more than the value following from the reduced mass ratio (1.0227) that is typical of Cbonded carbonyl species. We can thus conclude that this is the band of monocarbonyl species bound to $\mathrm{A} \mathrm{Ni}^{+}$ion. The same kind of simple isotopic shift is observed for $\mathrm{CO}$ adsorbed on bridged or silanol hydroxyls groups: the bands at 2180 and $2158 \mathrm{~cm}^{-1}$ shift to 2131 and $2109 \mathrm{~cm}^{-1}$, respectively, that corresponds in both cases almost exactly to the factor of 1.0227 .

After removal the most of $\mathrm{H}$-bonded $\mathrm{CO}$ and before the appearance of the bands of dicarbonyls a pair of bands can be seen in the spectrum of adsorbed ${ }^{12} \mathrm{CO}$ at 2124 and $2114 \mathrm{~cm}^{-1}$. One more band of the same compound can be clearly seen at $2158.0 \mathrm{~cm}^{-1}$ in the difference spectrum after subtracting the spectrum with the superimposing band of $\mathrm{CO}$ adsorbed on silanol groups. Corresponding bands of adsorbed ${ }^{13} \mathrm{CO}$ were found at $2108.5,2075$ and $2066.5 \mathrm{~cm}^{-1}$. This species should be unequivocally attributed to $\mathrm{Ni}^{+}\left({ }^{13} \mathrm{CO}\right)_{3}$. Spectra of isotopic mixtures were rather complicated, but after subtracting the spectra of adsorbed ${ }^{12} \mathrm{CO}$ and ${ }^{13} \mathrm{CO}$ in the region of interest there remained six main bands, which were assigned to $\mathrm{Ni}^{+}\left({ }^{12} \mathrm{CO}\right)_{2}\left({ }^{13} \mathrm{CO}\right)$ and $\mathrm{Ni}^{+}\left({ }^{12} \mathrm{CO}\right)\left({ }^{13} \mathrm{CO}\right)_{2}$, as proposed below in Table 1. The spectra of tricarbonyls are close to those obtained earlier by Hadjiivanov et al for Ni-ZSM-5 $[5,17,18]$, who observed the bands of $\mathrm{Ni}^{+}\left({ }^{12} \mathrm{CO}\right)_{3}$ at 2156, 2124, $2109 \mathrm{~cm}^{-1}$, and those of $\mathrm{Ni}^{+}\left({ }^{13} \mathrm{CO}\right)_{3}$ at $2110,2078,2061 \mathrm{~cm}^{-1}$. Very close frequencies of mono-, diand tricarbonyl species were reported also for Ni-BEA [20] zeolites.

If we turn to the next stage of $\mathrm{CO}$ desorption, when two bands are seen in the spectrum of pure isotopomers, the shifts and relative intensities of individual bands are better seen in simplified decomposition to gaussian curves shown in Figure 8. 


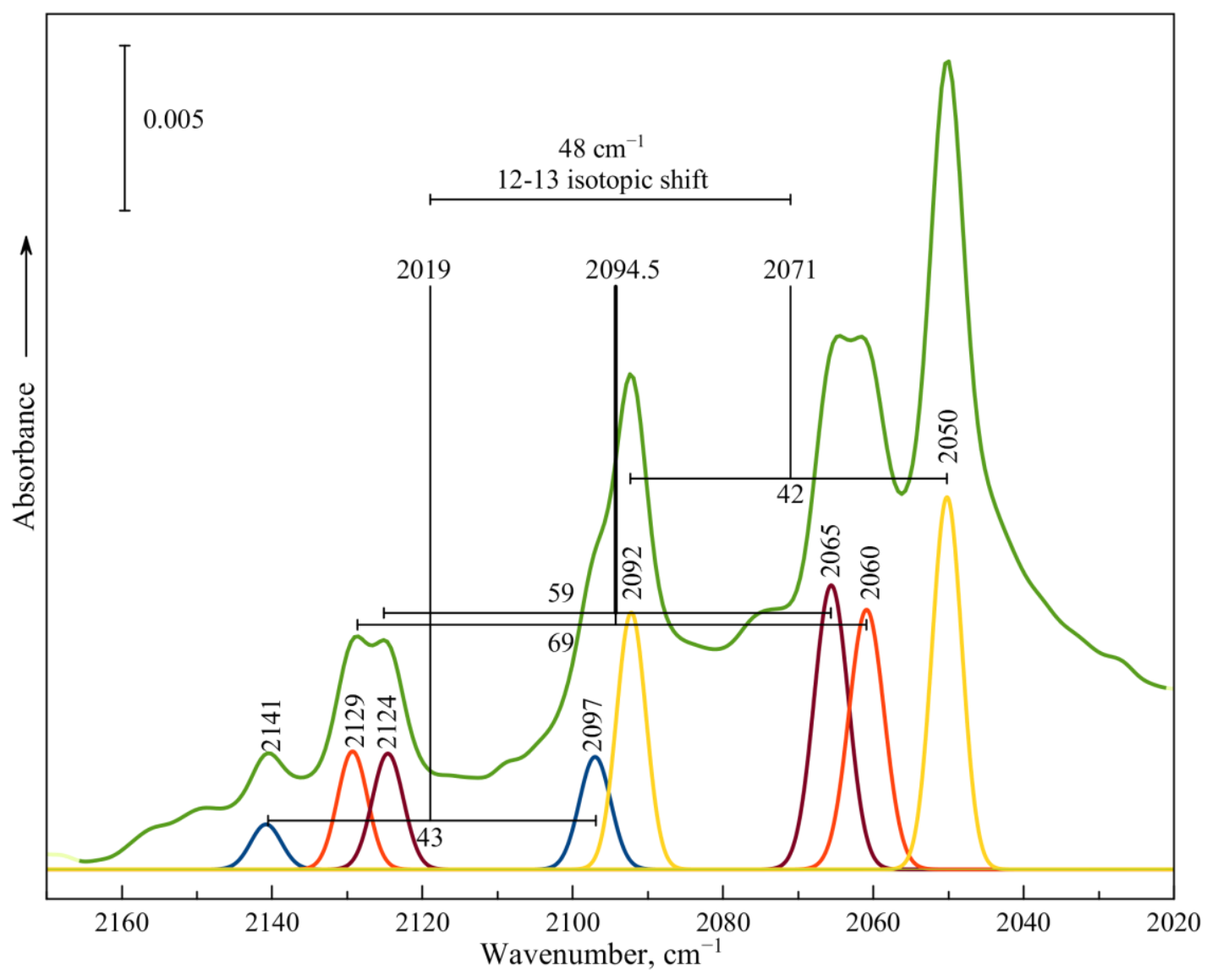

Figure 8. FTIR spectrum of $72 \%{ }^{13} \mathrm{CO}+28 \%{ }^{12} \mathrm{CO}$ mixture adsorbed on Ni10/H-USY after pumping for $15 \mathrm{~min}$ in the cooled cell with subsequent addition of 0.1 Torr of $\mathrm{He}$ at $77 \mathrm{~K}$; and the result of its deconvolution.

The pair of bands of adsorbed ${ }^{12} \mathrm{CO}$ at 2141 and $2097 \mathrm{~cm}^{-1}$, preceding the appearance of monocarbonyl, and their ${ }^{13} \mathrm{CO}$ analogues at 2091.5 and $2050 \mathrm{~cm}^{-1}$ are certainly due to dicarbonyl complexes $\mathrm{Ni}^{+}\left({ }^{12} \mathrm{CO}\right)_{2}$ and $\mathrm{Ni}^{+}\left({ }^{13} \mathrm{CO}\right)_{2}$. Again, we can state that isotopic ratios, 1.0237 and 1.0229 are close to the theoretically expected value. Not evident is the assignment of two pairs of bands observed simultaneously with the bands of the above dicarbonyl species on adsorption of ${ }^{12} \mathrm{CO}+{ }^{13} \mathrm{CO}$ isotopic mixtures at 2129, 2125 and 2065, $2061 \mathrm{~cm}^{-1}$. According to the conditions of the experiment, these bands should be associated with the dicarbonyls of mixed isotopic composition $\mathrm{Ni}^{+}\left({ }^{12} \mathrm{CO}\right)\left({ }^{13} \mathrm{CO}\right)$. To explain the band positions we have to take into account that the splitting between the two bands of $\mathrm{Ni}^{+}\left({ }^{12} \mathrm{CO}\right)_{2}$ caused by a strong dipole coupling between the two molecules is $44 \mathrm{~cm}^{-1}$, almost as great as the isotopic shift (about $48 \mathrm{~cm}^{-1}$ ). This means that the resonance should take place between the vibrations of molecules of different isotopic compositions, leading to the increase of the isotopic shift up to the observed values of $2129-2061=68 \mathrm{~cm}^{-1}$. Besides the usual isotopic shift of $48 \mathrm{~cm}^{-1}$, the latter value includes the contribution of resonance coupling equal in this case to $\mathrm{ca} 20 \mathrm{~cm}^{-1}$.

Another problem is to explain the appearance of four bands instead of two. The presence of extra bands can be the result of site heterogeneity. One pair of bands, say, the high-frequency components at 2129 and $2065 \mathrm{~cm}^{-1}$, can be assigned to dicarbonyls on one kind of sites, while another - those at lower wavenumbers of 2125 and $2061 \mathrm{~cm}^{-1}$ - on other sites, somehow different. But in this case the presence of different sites should be reflected in the spectra of 
monocarbonyls or dicarbonyls of pure isotopic composition. But the bands of the latter species are sharp, without any splitting or even broadening. Thus, the sites are identical, and the dissimilarity between two molecules bound to the same $\mathrm{Ni}^{+}$site originates from their way of linkage to it if they form a binary complex. The two molecules are not equivalent, and if one, e.g. ${ }^{12} \mathrm{CO}$ is in a position corresponding to slightly higher absorption frequency, another, ${ }^{13} \mathrm{CO}$ in our case, should be in such a position, that its frequency will be additionally lowered, and the distance between the bands, which includes the isotopic shift and the contribution from the resonance coupling will be additionally increased. Otherwise, the position of the ${ }^{13} \mathrm{CO}$ band will be moved upwards, then the frequency of the partner ${ }^{12} \mathrm{CO}$ molecule should be lowered, and the total splitting will be smaller. The latter case corresponds to the pair of bands at 2125 and 2065 with the splitting of $c a 60 \mathrm{~cm}^{-1}$. For isotopically pure dicarbonyls with two identical molecules, such as $\mathrm{Ni}^{+}\left({ }^{12} \mathrm{CO}\right)_{2}$, it is of no importance, which of them occupies what position, and there is no splitting. We have not detected any splitting of the bands of tricarbonyls of the mixed isotopic composition, although one cannot be sure that there is no additional broadening because of a great number of superimposed bands.

One can state that we deal with an interesting case of linkage isomerism of adsorbed CO molecules, when two dicarbonyl structures can be distinguished spectroscopically if they consist of two different isotopomers. Unlike usual isomerism when $\mathrm{CO}$ molecule can be bound to the cation either via carbon or oxygen, and the two structures not only vary in frequencies, but have different adsorption energies [21], in our case both have equal energies, but their dissimilarity is clearly manifested in their spectra. We cannot say yet firmly, what is the origin of their difference. It can be somehow connected with their orientation with respect to the environment. For instance, two CO molecule approach the $\mathrm{Ni}^{+}$site from two different sides, such as from the hexagonal prism or from the supercage. However, the difference is observed only when the second molecule is added to one already adsorbed. For monocarbonyls the molecules are bound to $\mathrm{Ni}^{+}$sites in one similar way, and do not manifest any sign of alternative adsorption, since the $2118 \mathrm{~cm}^{-1}$ band is narrow, symmetric and has not any hint on splitting or broadening neither at $77 \mathrm{~K}$, nor at ambient temperature.

Table 1 Positions of band maxima in the spectra of $\mathrm{CO}$ adsorbed on Ni-USY zeolite*

\begin{tabular}{|c|l|l|l|l|l|}
\hline Type & $\begin{array}{l}\text { Chemical } \\
\text { structure }\end{array}$ & \multicolumn{2}{|l|}{ Band wavenumber, $\mathrm{cm}^{-1}$} & $\begin{array}{l}\text { Center of } \\
\text { mass }\end{array}$ \\
\hline \multirow{4}{*}{ Monocarbonyls } & $\mathrm{Ni}^{+}\left({ }^{12} \mathrm{CO}\right)$ & 2118 & & & \\
\cline { 2 - 6 } & $\mathrm{Ni}^{+}\left({ }^{13} \mathrm{CO}\right)$ & 2069 & & & \\
\hline \multirow{5}{*}{ Dicarbonyls } & $\mathrm{Ni}^{+}\left({ }^{12} \mathrm{CO}\right)_{2}$ & 2141 & 2097 & & 2119 \\
\cline { 2 - 6 } & $\mathrm{Ni}^{+}\left({ }^{12} \mathrm{CO}\right)\left({ }^{13} \mathrm{CO}\right)$ & 2129. & 2061 & & 2095 \\
\cline { 2 - 6 } & 2125.0 & 2065. & & 2095 \\
\cline { 2 - 6 } & $\mathrm{Ni}^{+}\left({ }^{13} \mathrm{CO}\right)_{2}$ & 2091 & 2050 & & 2114 \\
\hline \multirow{5}{*}{ Tricarbonyls } & $\mathrm{Ni}^{+}\left({ }^{12} \mathrm{CO}\right)_{3}$ & 2158 & 2124 & 2132 \\
\cline { 2 - 6 } & $\mathrm{Ni}^{+}\left({ }^{12} \mathrm{CO}\right)_{2}\left({ }^{13} \mathrm{CO}\right)$ & 2149 & 2120 & $2089 ?$ & 2119 \\
\cline { 2 - 6 } & $\mathrm{Ni}^{+}\left({ }^{12} \mathrm{CO}\right)\left({ }^{13} \mathrm{CO}\right)_{2}$ & 2138 & 2086 & $2076 ?$ & 2100 \\
\cline { 2 - 6 } & $\mathrm{Ni}^{+}\left({ }^{13} \mathrm{CO}\right)_{3}$ & 2108 & 2075 & 2066 & 2083 \\
\hline
\end{tabular}

* the frequency values observed at $77 \mathrm{~K}$.

The method of isotopic dilution enables us to distinguish static and dynamic (resonance) interaction between the adsorbed molecules. In our case the splitting between the two bands of dicarbonyls is a manifestation of strong resonance dynamic interaction. The static interaction is comparatively strong and repulsive. In fact, to remove the first molecule from tricarbonyl pumping 
of frozen cell is enough. Next molecule can be desorbed by evacuation at room temperature, but the last CO molecule resist even pumping at $373 \mathrm{~K}$. Repulsive static interaction manifests itself in the shift of the band of adsorbed molecules from the position determined by adsorption interaction in the direction to that of a free molecule, diminishing the shift caused by adsorption. For $\mathrm{ZnO}$ the frequency of coordinately adsorbed molecules, which increases from 2143 up to $2192 \mathrm{~cm}^{-1}$ due to adsorption, is lowered because of static interaction up to $2162 \mathrm{~cm}^{-1}$ [22]. In our case the mean value of two bands of dicarbonyl $\left(2119 \mathrm{~cm}^{-1}\right)$ almost coincides with the position of monocarbonyl $\left(2018 \mathrm{~cm}^{-1}\right)$, while the addition of the third molecule moves the mean frequency value to $2132 \mathrm{~cm}^{-1}$ (see Table 1). The shift upwards reflects the weakening of backdonation with the increasing number of ligands, the kind of static shift in our case. The initial frequency shift from the value of a free molecule $\left(2143 \mathrm{~cm}^{-1}\right)$ diminishes from 25 up to $11 \mathrm{~cm}^{-1}$, for the third molecule, but not for the second one, although the energy of adsorption is much lower, than for the first. This could mean that two molecules in dicarbonyl do not feel repulsion between each other, but adsorption of the second weakens the bond of both with the cation. For oxides static interaction is enhanced by the solid due to the effect of relaxation induced by adsorption [23], i.e. the changing of interatomic distances in the superficial layer. The absence of such effect on adsorption of the second molecule can be understood as an evidence for adsorption of two molecules at the same cation, but not on two neighboring atoms in a cluster or on an oxocation such as $(\mathrm{Ni}-\mathrm{O}-\mathrm{Ni})^{+2}$.

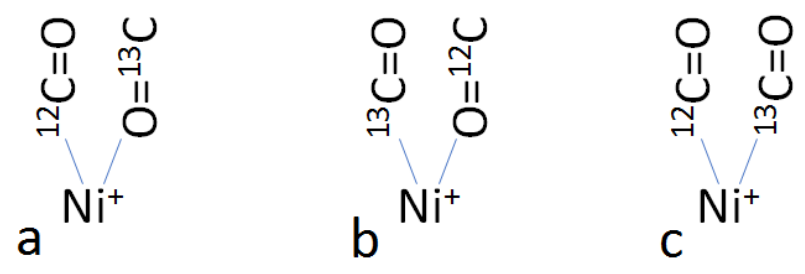

Figure 9. Possible $\mathrm{Ni}^{+}$dicarbonyl configurations.

The properties of dicarbonyl species can be illustrated by the above scheme (Figure 9), where two molecules are coordinated in different way to the same $\mathrm{Ni}^{+}$ion, and thus, structures $a$ and $b$ have different frequencies. The dipoles of the two molecules are oriented in opposite directions and there is no direct repulsion of dipoles. Back donation of d-electrons of $\mathrm{Ni}$ to $\mathrm{CO}$ molecules makes them close to NO, which has a tendency to form dimers. If the interaction between the molecules becomes attractive, there is no reason for the mean frequency to increase with respect to monocarbonyl, and the formation of dicarbonyl of two C-bonded molecules (Figure 9 structure $c$ ) turns to be energetically less favorable. The possibility to form such a structure with non-equivalent molecules crucially depends on the properties of the metal, then it is not by chance that it was found only for nickel which has unique properties as a catalyst for the Sabatier reaction. Of course, this is only a hypothesis, and to establish the real structure of the dicarbonyl we need quantum chemical modeling and extra experimental date. However, the finding of such isotopic isomerism itself seems to be important and worth further investigation.

\section{Conclusions}

The study of $\mathrm{CO}$ adsorption on reduced $\mathrm{Ni}$-containing USY zeolites with $\mathrm{Si} / \mathrm{Al}=30$ has been carried out by means of FTIR spectroscopy at variable temperatures. The bands of bridged $\mathrm{OH}$ groups of both initial H-USY and Ni-loaded samples are unusually narrow. The same can be said about the band of perturbed hydroxyls and adsorbed CO. Apparently, this is due to the high Si/Al ratio. The spectra of 
$\mathrm{CO}$ adsorbed on Ni-containing zeolites, also with extremely sharp bands, change dramatically with the coverage. Three bands at 2152, 2124 and $2114 \mathrm{~cm}^{-1}$, which disappear after evacuation of the cell, cooled with liquid nitrogen, should be assigned to tricarbonyls $\mathrm{Ni}^{+}(\mathrm{CO})_{3}$. The remaining dicarbonyls, characterized by two distinct bands at 2141 and $2097 \mathrm{~cm}^{-1}$, can be eliminated by evacuation at $300 \mathrm{~K}$, leaving monocarbonyl, which has a sharp band at $2118 \mathrm{~cm}^{-1}$ (at $77 \mathrm{~K}$ ).

The surface nickel dicarbonyl species exhibit an interesting phenomenon that can be called isotopic isomerism, when two CO molecules occupy not equivalent positions, and the spectrum of isotopically mixed species has two pairs of bands, slightly differing from each other. As an explanation illustrating such possibility, a structure of two molecules is proposed, where one CO molecule is bound to $\mathrm{Ni}^{+}$cation via carbon, another- via oxygen atom.

\section{Acknowledgement.}

The work was supported by RFBR and CITMA, grant No. 18-53-34004. R.B. is grateful to the Ministère des Affaires Etrangères Français for the Metchnikov scholarship.

\section{References:}

[1] X. Su, J. Xu, B. Liang, H. Duan, B. Hou, Y. Huang, J. Energy Chem. 25 (2016) 553-565.

[2] I. Graça, L. V. González, M.C. Bacariza, A. Fernandes, C. Henriques, J.M. Lopes, M.F. Ribeiro, Appl. Catal. B Environ. 147 (2014) 101-110.

[3] F. Thibault-Starzyk, F. Maugé, in: J.V. M.Che (Ed.), Charact. Solid Mater. Heterog. Catal. From Struct. to Surf. React., Wiley, 2012, pp. 1-48.

[4] G. Busca, Phys. Chem. Chem. Phys. 1 (1999) 723-736.

[5] K.I. Hadjiivanov, G.N. Vayssilov, Adv. Catal. 47 (2002) 307-511.

[6] S. Bordiga, C. Lamberti, F. Bonino, A. Travert, F. Thibault-Starzyk, Chem. Soc. Rev. 44 (2015) 7262-7341.

[7] E. Dooryhee, C.R.A. Catlow, J.W. Couves, P.J. Maddox, J.M. Thomas, G.N. Greaves, A.T. Steel, R.P. Townsend, J. Phys. Chem. 95 (1991) 4514-4521.

[8] P. Gallezot, Y. Ben Taarit, B. Imelik, J. Catal. 26 (1972) 481-483.

[9] T.A. Egerton, J.C. Vickerman, J. Chem. Soc. Faraday Trans. 1 Phys. Chem. Condens. Phases 261 (1973) 39-49.

[10] C.O. Arean, O. Manoilova, A. Tsyganenko, G.T. Palomino, M. Mentruit, F. Geobaldo, E. Garrone, Eur.J.Inorg.Chem. (2001) 1739-1743.

[11] C.W. Hu, J. Yao, H.Q. Yang, Y. Chen, A.M. Tian, J. Catal. 166 (1997) 1-7.

[12] O. Cairon, T. Chevreau, J.-C. Lavalley, J. Chem. Soc. Faraday Trans. 94 (1998) 3039-3047.

[13] A.A. Tsyganenko, E. V. Kondratieva, V.S. Yanko, P.Y. Storozhev, J. Mater. Chem. 16 (2006) 2358.

[14] P.Y. Storozhev, C. Otero Areán, E. Garrone, P. Ugliengo, V.. Ermoshin, A.. Tsyganenko, Chem. Phys. Lett. 374 (2003) 439-445.

[15] G. Busca, Microporous Mesoporous Mater. 254 (2017) 3-16.

[16] P. Gallezot, Y.Ben Taarit, B. Imelik, J. Phys. Chem. 77 (1973) 2556-2560.

[17] A.I. Serykh, M.D. Amiridis, J. Phys. Chem. C 111 (2007) 17020-17024.

[18] K.I. Hadjiivanov, H. Knözinger, M.Y. Mihaylov, J. Phys. Chem. B 106 (2002) 2618-2624.

[19] H.A. Aleksandrov, V.R. Zdravkova, M.Y. Mihaylov, P.S. Petkov, G.N. Vayssilov, K.I. Hadjiivanov, J. Phys. Chem. C 116 (2012) 22823-22831. 
[20] A. Penkova, S. Dzwigaj, W.R. Kefirov, K. Hadjiivanov, M. Che, J. Phys. Chem. C 111 (2007) 8623-8631.

[21] C.O. Areán, G.T. Palomino, A.A. Tsyganenko, E. Garrone, Int. J. Mol. Sci. 3 (2002) 764-776.

[22] L.A. Denisenko, A.A. Tsyganenko, V.N. Filimonov, React. Kinet. Catal. Lett. 25 (1984) 23-26.

[23] A.A. Tsyganenko, S.M. Zverev, React. Kinet. Catal. Lett. 36 (1988) 269-274. 


\title{
Deep insight into CO adsorption on Ni-USY zeolite catalyst by FTIR spectroscopy. Evidence for isotopic isomerism
}

\author{
R.Belykh ${ }^{1}$, F.Mauge ${ }^{2}$, A.Tsyganenko ${ }^{1}$ \\ ${ }^{1}$ V. A. Fock Institute of Physics, St. Petersburg State University, St. Petersburg, 198504, Russia, \\ ${ }^{2}$ Laboratoire Catalyse et Spectrochimie, ENSICAEN - Université de Caen Normandie - CNRS, 6 \\ Boulevard du Maréchal Juin, 14050 Caen Cedex, France
}

\begin{abstract}
FTIR spectra of $\mathrm{CO}$ adsorbed on reduced $\mathrm{Ni}$-containing USY zeolites with $\mathrm{Si} / \mathrm{Al}=30$ besides weak $\mathrm{H}$ bond with bridged hydroxyls and silanol groups and bonding to $\mathrm{Ni}^{2+}$ cations reveal formation of mono-, di- and tricarbonyls with $\mathrm{Ni}^{+}$sites. The bands of adsorbed $\mathrm{CO}$ species are very narrow, with FWMH $1-1.5 \mathrm{~cm}^{-1}$. The spectra of isotopically mixed nickel dicarbonyl species reveal the splitting, which shows that two CO molecules occupy non-equivalent positions, so that the species exist in two isomeric forms, despite the similarity of sites, following from the spectra of monocarbonyls. Possible explanations of this phenomenon are discussed.
\end{abstract}

\section{Introduction}

The Sabatier reaction of $\mathrm{CO}_{2}$ hydrogenation gets into public attention as a method to produce methane from renewable energy sources. It was even mentioned in ambitious projects for interplanetary spaceflights. The reaction requires $\mathrm{CO}_{2}, \mathrm{H}_{2}$ and an active catalyst. The catalysts for Sabatier process usually consist of oxide support and transition metal, almost always nickel, although both parts can be varied.[1]

We have focused our research on zeolite-based Ni catalysts, for they show high conversion and selectivity [2] while the materials are relatively cheap. However, is not clear yet, which characteristics of nickel account for its specific catalytic properties.

IR spectroscopy was used as the main method in this study, since it provides detailed information about surface complexes of adsorbed molecules [3],[4], and is successfully applied in operando catalytic studies. IR spectra of CO adsorbed on HY zeolites are thoroughly studied [5],[6]. Spectra of $\mathrm{CO}$ adsorbed on $\mathrm{Ni}$-impregnated zeolites were also investigated, and the results show high sensitivity to the charge of $\mathrm{Ni}$ ions.

Other methods show that $\mathrm{Ni}$ state in zeolites is not strictly determined [7]. Impregnated $\mathrm{Ni}^{2+}$ ions upon dehydration populate hexagonal prisms [8]. Maximum population is 12 ions per unit cell, and when the loading exceeds this value the increase in metallic $\mathrm{Ni}^{\circ}$ concentration should be expected. NMR data [9] infer that $\mathrm{Ni}^{2+}$ ions in $\mathrm{Y}$ zeolites can move outside hexagonal prism to sodalite cages at $673 \mathrm{~K}$. The process is reversible and depends on the amount of water present. Some $\mathrm{Ni}$ ions stay in exchange positions, with $2+$ charge, others stick together, possibly keeping charge disbalance, creating unusual weakly-charged surfaces. $\mathrm{Ni}^{+}$sites in Ni-ZSM-5 are stable up to 
moderately high temperatures $(550-600 \mathrm{~K})$. At higher temperatures, the $\mathrm{Ni}^{+}$sites are converted to $\mathrm{Ni}^{0}$ and $\mathrm{Ni}^{2+}$ in the disproportionation reaction. [7]

In this study we have investigated the properties of $\mathrm{Ni}$ centres with $\mathrm{CO}$ as a probe molecule. Comparatively narrow bands in the spectra of $\mathrm{Y}$ zeolites with high Si/Al ratios facilitate application of isotopic substitution for establishing the structure of surface species.

\section{Experimental}

Ultrastable Y-zeolite (USY) in $\mathrm{H}$ form with $\mathrm{Si} / \mathrm{Al}$ ratio of 30 was purchased from Zeolyst (CBV760). Ni was introduced by incipient wet impregnation. Water solution of $\mathrm{Ni}\left(\mathrm{NO}_{3}\right)_{2} \cdot 6 \mathrm{H}_{2} \mathrm{O}$, (chem. pure) was prepared in quantity close to total pore volume of the zeolite in a portion and with proper concentration to get 10 (denoted below as $\mathrm{Ni10}$ ) or 14 ( $\mathrm{Ni14}$ ) weight percent loading of $\mathrm{Ni}$. The solution was added dropwise to zeolite dried at $353 \mathrm{~K}$ overnight, under constant stirring in mortar. When all the solution added, the sample was a homogeneous heavy powder of light-green color. After impregnation the catalyst was dried at $413 \mathrm{~K}$ at least for two hours and calcined at $773 \mathrm{~K}$ under air flow for 5 hours. The temperature changing rate was around $5 \mathrm{~K} / \mathrm{min}$. After calcination the colour of the sample becomes light-grey.

For spectral studies batches of powder were pressed into self-supported pellets in a form of disks, roughly $15 \mathrm{mg}$ per $2.0 \mathrm{~cm}^{2}$. Then a rectangle was cut from the disk, to fit in the homemade sample-holder. The sample was inserted into the low-temperature IR cell described elsewhere [10] and activated in-situ. The samples were heated at $413 \mathrm{~K}$ for two hours under constant pumping by a turbomolecular pump, and then the temperature was increased up to $723 \mathrm{~K}$ at the rate of $5 \mathrm{~K} / \mathrm{min}$.

For Ni loaded samples, $\mathrm{H}_{2}$ was introduced at $\mathrm{T}=723 \mathrm{~K}$, up to the pressure of about 40 Torr in the sample volume. The sample volume was connected to a trap cooled with liquid nitrogen, so that water formed during the reduction would be frozen there. After 30 minutes the rest of $\mathrm{H}_{2}$ was removed by pumping and another portion of $\mathrm{H}_{2}$ was introduced. The activated sample was slowly cooled down to $77 \mathrm{~K}$ in the low part of the cell, about 0,5 Torr of He was introduced in the sample volume in order to improve thermal contact of the sample with the cold cell walls, and the reference spectrum of the clean sample was recorded. Afterwards it could be subtracted from the spectra with adsorbed CO.

$\mathrm{CO}$ gas of chemical purity or its mixture with ${ }^{13} \mathrm{CO}$ was introduced through a trap cooled by liquid nitrogen into sample volume of the cell kept at $77 \mathrm{~K}$ by several portions, until the saturation of surface sites was reached at equilibrium $\mathrm{CO}$ pressure of $1-5$ Torr. Then $\mathrm{CO}$ was removed by pumping for certain time, followed by re-filling the cell by a new portion of He. The procedure was repeated several times, first with the sample in the cooled part of the cell, then it was moved up into the quartz tube for evacuation at $300 \mathrm{~K}$ or at elevated temperature, if needed. At every stage of adsorption or desorption spectra were recorded with the typical resolution of $2 \mathrm{~cm}^{-1}$, sometimes even $1 \mathrm{~cm}^{-1}$ to estimate the width of narrow bands.

Inductively Coupled Plasma Mass Spectrometry analysis for $\mathrm{Si}, \mathrm{Al}, \mathrm{Na}, \mathrm{Ni}$ concentration provided the data on Ni loading, which turned to be 10.2 and 13,7 weight percent for Ni10/H-USY and Ni14/H-USY, respectively, close enough to the desired values of 10 or $14 \%$ of the metal. 


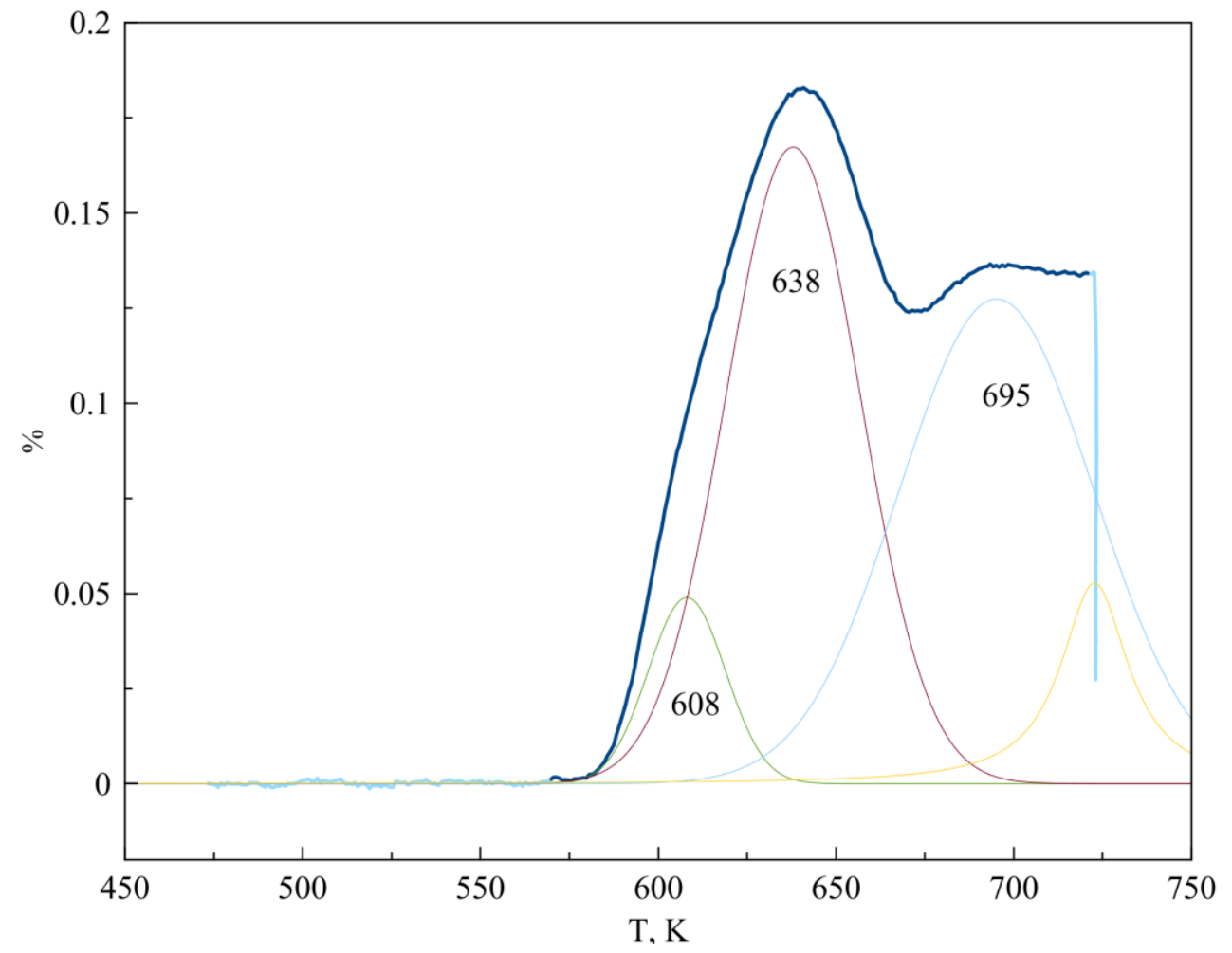

Figure 1 Temperature Programmed Reduction curve for Ni10/H-USY sample.

TPR experiments show (Figure 1) three maxima of reduction on heating up to $723 \mathrm{~K}$ in $75 \% \mathrm{Ar}$ $25 \% \mathrm{H}_{2}$ flow at temperatures 608,638 and $695 \mathrm{~K}$. Taking into account that pure Ni oxides are reduced in one-step process at distinct temperatures: $611 \mathrm{~K}$ for $\mathrm{Ni}_{2} \mathrm{O}_{3}$ and $678 \mathrm{~K}$ for $\mathrm{NiO}$ [11], we assume that the shoulder at $608 \mathrm{~K}$ corresponds to small amount of $\mathrm{Ni}^{3+}$, while maxima at 638 and $695 \mathrm{~K}$ are due to transformations of $\mathrm{Ni}^{2+}$ to $\mathrm{Ni}^{+}$and further reduction to $\mathrm{Ni}^{0}$ metal. These reduction temperatures are lower than given in literature for pure Ni oxides. 


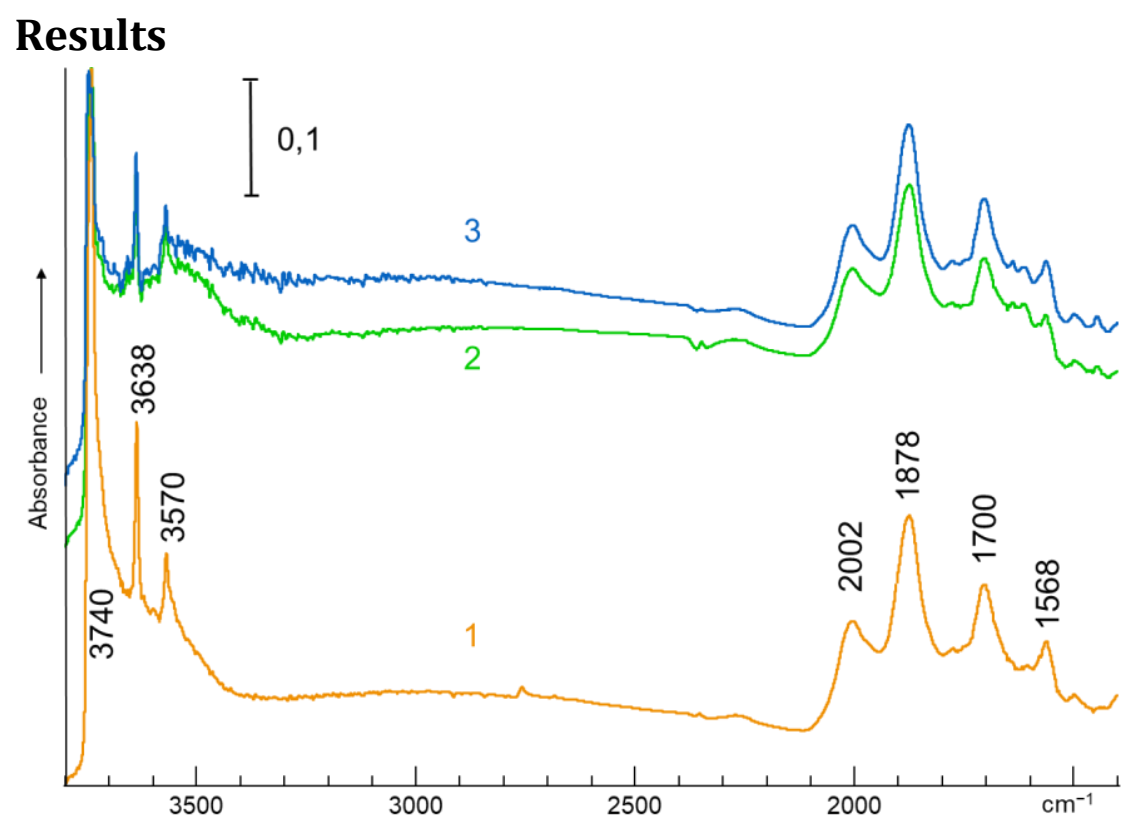

Figure 2. IR spectra of USY samples with $\mathrm{O}(1), 10$ (2) and 14 (3) weight percent of $\mathrm{Ni}$, activated at $723 \mathrm{~K}$ and registered at $77 \mathrm{~K}$.

The spectra of activated support zeolite and metal-loaded samples are shown in Figure 2. In the $\mathrm{OH}$ stretching region one can see the band at 3738 , which at $77 \mathrm{~K}$ reveals a structure of three maxima at 3747,3740 and $3735 \mathrm{~cm}^{-1}$, at 3638 and $3570 \mathrm{~cm}^{-1}$ attributed to silanol, supercage and sodalite cage $\mathrm{OH}$ groups, respectively [6]. Bands at $2002 \mathrm{~cm}^{-1}$ and below are due to zeolite framework vibrations. Even if the spectra are normalized to the same intensity of the framework bands, we can state that the introduction of $\mathrm{Ni}$ leads to the decreased intensities of $\mathrm{OH}$ groups with the possible exception of that one at $3570 \mathrm{~cm}^{-1}$.

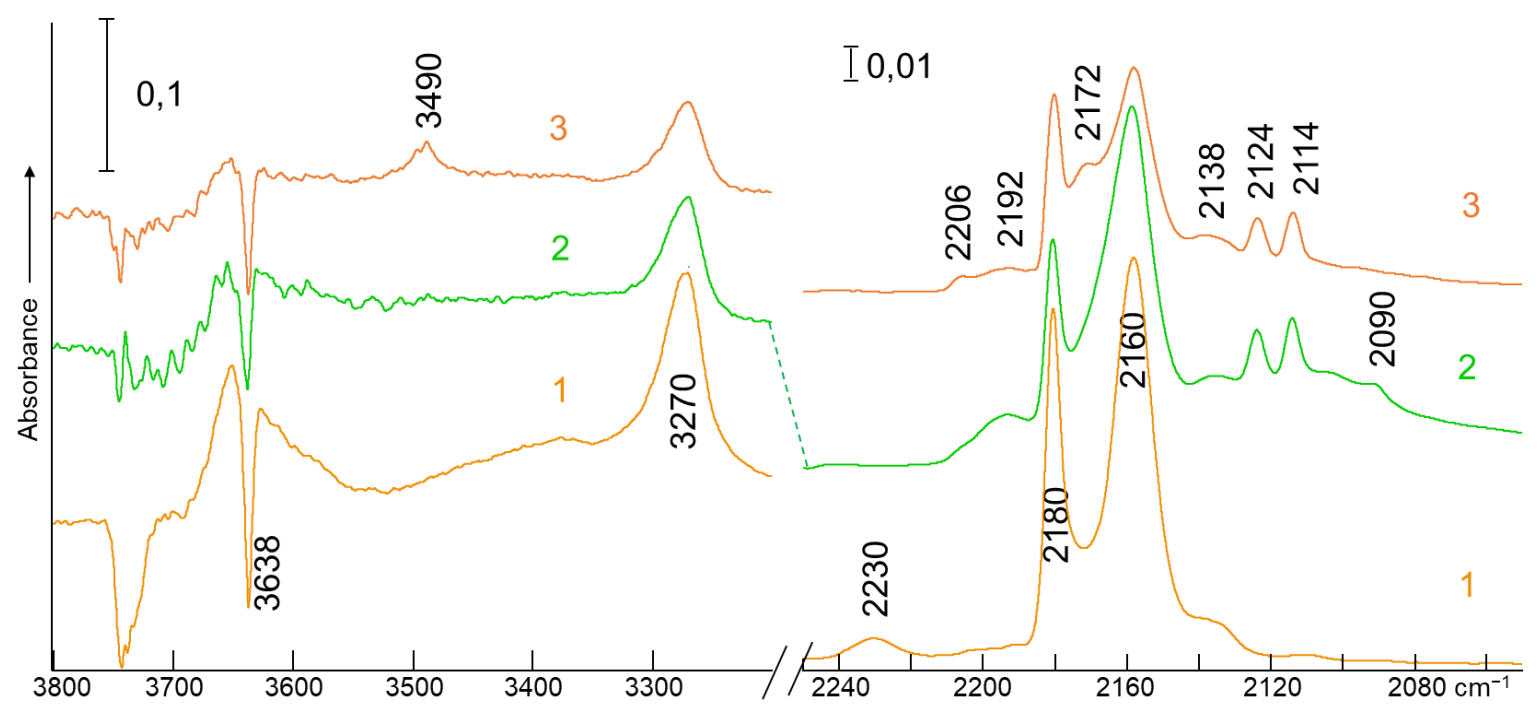

Figure 3. FTIR spectra of ${ }^{12} \mathrm{CO}$ adsorbed on H-USY (1), Ni10/H-USY (2) and Ni14/H-USY (3) at $77 \mathrm{~K}$ with 0.2 Torr He in the cell. The spectrum of the sample before adsorption is subtracted.

Addition of the first doses of $\mathrm{CO}$ to all the three studied samples in the cell, preliminary cooled with liquid nitrogen (Figure 3), results in the intensity decrease of the $\mathrm{OH}$ band at 3638 with simultaneous growth of the band of perturbed hydroxyls at $3270 \mathrm{~cm}^{-1}$ and a band of adsorbed ${ }^{12} \mathrm{CO}$ 
at $2180 \mathrm{~cm}^{-1}$. If the pressure of $\mathrm{CO}$ in the cell increases up to $1-5$ Torr an intense band at $2158 \mathrm{~cm}^{-1}$ grows simultaneously with the band at about $3650 \mathrm{~cm}^{-1}$ and the decrease of silanol band at $c a$ $3740 \mathrm{~cm}^{-1}$. One more band at $2138 \mathrm{~cm}^{-1}$ increases in intensity and moves to $2140 \mathrm{~cm}^{-1}$ with the growing coverage.

Other bands are not the same for different samples, as can be seen from Figure 3. A weak band at $2230 \mathrm{~cm}^{-1}$ arises in the spectrum of H-USY zeolite. In the spectra of Ni-loaded samples along with the bands of $\mathrm{CO}$ adsorbed on hydroxyl groups one can see a couple of bands at 2206 and $2192 \mathrm{~cm}^{-1}$ and a pair of very narrow $\left(\Delta \mathrm{v}_{1 / 2}<1.5 \mathrm{~cm}^{-1}\right)$ bands at 2124 and $2114 \mathrm{~cm}^{-1}$. A band at $2172 \mathrm{~cm}^{-1}$ is more prominent in the spectrum of Ni14/H-USY sample. It is present but rather weak for Ni10/H-USY sample, and absent for H-USY. It is accompanied by a slight change in the shape and position of the $3490 \mathrm{~cm}^{-1}$ band.

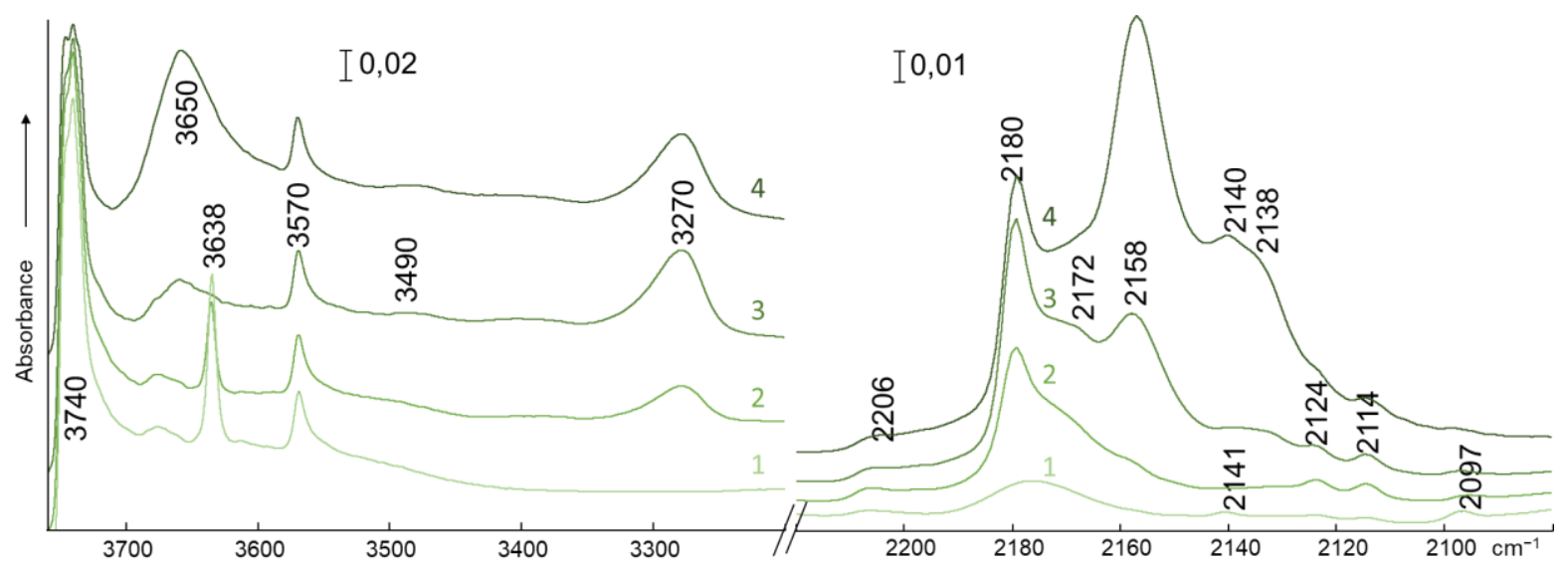

Figure 4. FTIR spectra of CO adsorbed on Ni14/H-USY by small doses admission. Coverage increases from 1 to 4 while the equilibrium pressure grows up to 1,48 Torr at $77 \mathrm{~K}$.

The process of $\mathrm{CO}$ gradual adsorption is illustrated in Figure 4. As there was no He in the cell in this experiment, the initial sample temperature was higher than $77 \mathrm{~K}$. The resulting picture is identical to that at the beginning of desorption process after full saturation of the surface. 3490 ?

The first to appear are the bands at 2180 and $3270 \mathrm{~cm}^{-1}$ accompanied by intensity decrease of the $3638 \mathrm{~cm}^{-1}$ band. The pair of weak bands at 2141 and $2097 \mathrm{~cm}^{-1}$ at curve 1 is replaced by those at 2124 and $2114 \mathrm{~cm}^{-1}$ (Figure 4 curve 2). The $2180 \mathrm{~cm}^{-1}$ band reaches its maximum intensity when the $3638 \mathrm{~cm}^{-1}$ band is completely gone (Figure 4 curve 3 ). The intensity of the band at $2172 \mathrm{~cm}^{-1}$ increases together with that at $3490 \mathrm{~cm}^{-1}$. The appearance of $2158 \mathrm{~cm}^{-1}$ band is accompanied by the growth of that at $3650 \mathrm{~cm}^{-1}$ and decrease of silanol band at $3740 \mathrm{~cm}^{-1}$. The last to appear are poorly resolved broad bands at $2140-2138 \mathrm{~cm}^{-1}$, they increase with the growing pressure of CO gas in the cell up to several Torr.

CO desorption is illustrated in Figure 5. As soon as the broad band at $2158 \mathrm{~cm}^{-1}$ is removed, much weaker narrow band at exactly the same position of maximum becomes visible. It disappears together with the bands at 2124 and $2114 \mathrm{~cm}^{-1}$ after prolonged evacuation of the cold cell when other bands of adsorbed $\mathrm{CO}$ are gone (Figure 5 curve 2) and the spectrum of surface $\mathrm{OH}$ groups is restored completely. Simultaneously, a new pair of narrow bands arises at 2141 and $2097 \mathrm{~cm}^{-1}$. 
Evacuation at $300 \mathrm{~K}$ leads to simultaneous disappearance of that pair while a new band appears at $2018 \mathrm{~cm}^{-1}$. This band resists pumping at $373 \mathrm{~K}$, but disappears after heating in vacuum at $473 \mathrm{~K}$.

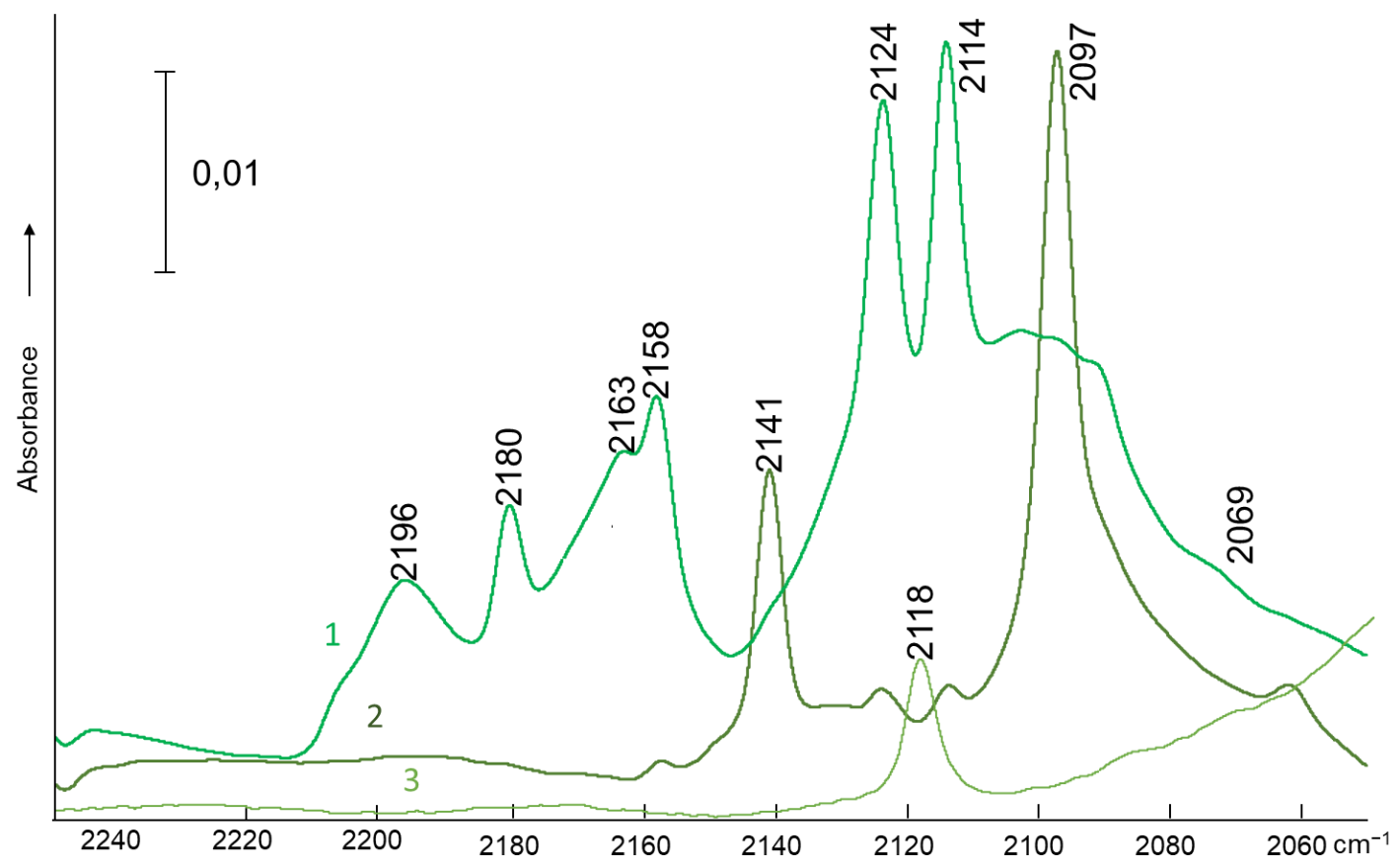

Figure 5. Spectra of ${ }^{12} \mathrm{CO}$ adsorbed on Ni10/H-USY at $77 \mathrm{~K}$, with 0.2 Torr of He present. Coverage decreases from top to bottom. 1 - pumped for 3 minutes, 2 - pumped for 10 minutes, 3 - pumped at room temperature for 10 minutes.

In order to clarify the interpretation of the results, the experiments with the mixtures of ${ }^{12} \mathrm{CO}$ and ${ }^{13} \mathrm{CO}$ were performed. Figure 6 shows the evolution of spectrum of such a mixture with about $70 \%$ of ${ }^{13} \mathrm{CO}$ on desorption. As shows the comparison of curves shown in this figure with the spectra of pure ${ }^{12} \mathrm{CO}$ from Figure 5, all the bands of ${ }^{12} \mathrm{CO}$ above $2158 \mathrm{~cm}^{-1}$ have their analogs simply shifted to the lower wavenumbers by about $49 \mathrm{~cm}^{-1}$. So, the band at 2180 and the broad one $2158 \mathrm{~cm}^{-1}$ are shifted to 2131 and $2109 \mathrm{~cm}^{-1}$, respectively. The sharp band of ${ }^{12} \mathrm{CO}$ at $2158 \mathrm{~cm}^{-1}$ is merged with the shifted analogs of absorption at $2206-2192 \mathrm{~cm}^{-1}$. The most stable band at $2018 \mathrm{~cm}^{-1}$ has its ${ }^{13} \mathrm{CO}$ analog at $2069 \mathrm{~cm}^{-1}$. Other weak bands observed below $2158 \mathrm{~cm}^{-1}$ produce more complicated picture in the spectrum of mixed isotopes. 


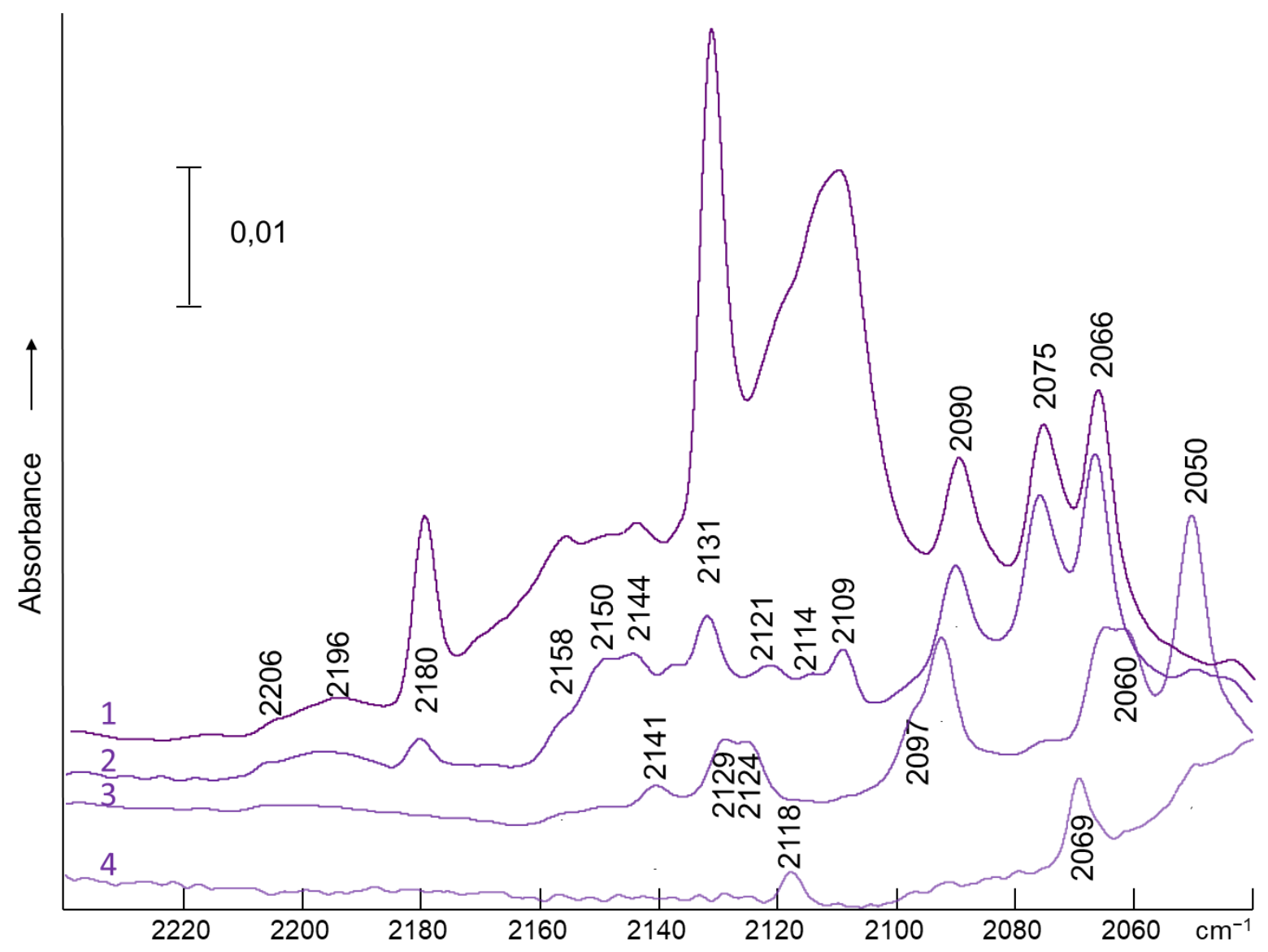

Figure 6. FTIR spectra of $28 \%{ }^{12} \mathrm{CO}+72 \%{ }^{13} \mathrm{CO}$ mixture desorbed from Ni10/H-USY. CO is pumped by turbomolecular pump for successively increased time at $77 \mathrm{~K}(1-3)$ and $300 \mathrm{~K}(4)$.

A pair of bands at 2141 and $2097 \mathrm{~cm}^{-1}$ have their ${ }^{13} \mathrm{CO}$ analogs at 2092 and $2050 \mathrm{~cm}^{-1}$, but simultaneously, at the conditions when no other bands are seen in the spectrum of pure ${ }^{12} \mathrm{CO}$, two close doublets are seen at $2129-2124$ and $2164-2160 \mathrm{~cm}^{-1}$. Even more complex spectrum arises before, when the weakly bound molecules are just removed, the bands of surface $\mathrm{OH}$ groups are mostly recovered, and the remaining ${ }^{12} \mathrm{CO}$ accounts for the pair of bands at 2124 and $2114 \mathrm{~cm}^{-1}$ and one more sharp band at $2158 \mathrm{~cm}^{-1}$. In attempt to assign the observed bands in this case we have run the spectra of mixtures of different enrichment, which have about 30 and $50 \%$ of ${ }^{13} \mathrm{CO}$. The results are shown in Fig. 7. Subtracting the spectrum of pure ${ }^{12} \mathrm{CO}$ from those of mixtures, we were able to obtain the spectrum of mixed isotopic species. The latter was subtracted from that of $70 \%{ }^{13} \mathrm{CO}$ with thus chosen factor that almost only the triplet of bands due to pure ${ }^{13} \mathrm{CO}$ species could be seen at 2109, 2075 and $2065 \mathrm{~cm}^{-1}$, exactly at the positions expected for the positions of completely substituted species if we shift the frequencies of corresponding ${ }^{12} \mathrm{CO}$ species down by $49 \mathrm{~cm}^{-1}$. Now, if we subtract this spectrum from that of a mixture with $50 \%$ enrichment, we obtain a spectrum of partly substituted species, shown in Figure 7 together with the spectra of pure ${ }^{12} \mathrm{CO}$ and ${ }^{13} \mathrm{CO}$ species, existing at this stage of $\mathrm{CO}$ desorption. The resulting spectrum displays at least 6 distinct bands whose position with the proposed assignment are shown below in Table 1. An extra band at about $2090 \mathrm{~cm}^{-1}$, which is present in curves 1 and 3, does not correlate with others and can be presumably assigned to $\mathrm{CO}$ adsorbed on $\mathrm{Ni}^{0}$. 


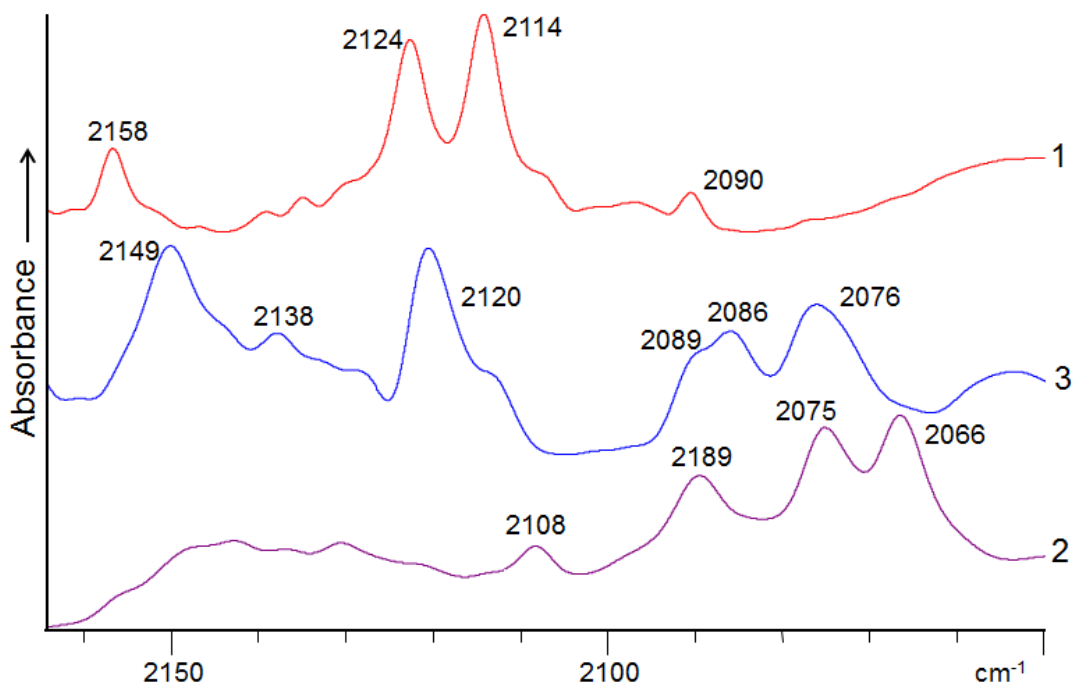

Figure 7. FTIR spectra of Ni tricarbonyl surface species of different isotopic compositions. $1-99 \%$ of ${ }^{12} \mathrm{CO}$, 2 - almost pure ${ }^{13} \mathrm{CO}$ obtained from $28 \%{ }^{12} \mathrm{CO}+72 \%{ }^{13} \mathrm{CO}$ mixture by subtraction of the spectrum of that of $\mathrm{ca} 50: 50 \%$; 3 - spectrum of $60 \%{ }^{12} \mathrm{CO}+40 \%{ }^{13} \mathrm{CO}$ mixture after subtraction of curves 1 and 2 .

\section{Discussion}

The observed spectrum of HUSY zeolite as well as of $\mathrm{CO}$ adsorbed on the $\mathrm{OH}$ groups of the studied samples are in agreement with the published data. The great $\mathrm{VOH}$ frequency shift $\left(\Delta \mathrm{vOH}=360 \mathrm{~cm}^{-1}\right)$ as well as the high position of the corresponding $\mathrm{vCO}$ band $\left(2180 \mathrm{~cm}^{-1}\right)$ testify for a high acidity of the hydroxyls, close to the highest values observed for zeolites [12]. Comparatively small width of the bands of $\mathrm{H}$-bonded $\mathrm{OH}$-groups, apparently, is due to homogeneity of the hydroxyl groups in their properties, typical of $\mathrm{Y}$ zeolites with high Si/Al ratio.

Unlike the latter band of zeolitic bridged $\mathrm{OH}$ groups, the band of silanol groups is broad and has the structure of several maxima. Apparently, these groups have different environment. Some of them can be located at exterior surface of microcrystals, others could be in the defects of inner surface. Their properties should be not the same, and it is not by chance that the band of CO bound to these groups is also broad and its band moves on desorption from 2158 to $2163 \mathrm{~cm}^{-1}$, where it can be seen in Figure 4.

The band at $2138-2140 \mathrm{~cm}^{-1}$ which appear at high coverages is usually considered as physisorption or liquid-like species, but the high enthalpy of adsorption $(11 \mathrm{~kJ} / \mathrm{mol}$ for silica against $6.044 \mathrm{~kJ} / \mathrm{mol}$ for condensation), and the downward frequency shift by $5-7 \mathrm{~cm}^{-1}$, not observed for liquid or dissolved CO infer that it is rather due to the side-on complexes with siloxane bridges [13]. Certain contribution to the intensity of the band at $2138 \mathrm{~cm}^{-1}$ make $\mathrm{CO}$ molecules bound to silanol groups via oxygen atom [14].

The band at $2230 \mathrm{~cm}^{-1}$, seen in the spectra of H-USY zeolites can be due to $\mathrm{CO}$ adsorbed on extraframework or even framework $\mathrm{Al}^{3+}$ ions from the supercage side [15]. In our case its appearance can mean that the sample was somehow damaged during the activation procedure if the pumping was not efficient enough to avoid hydrotreatment. 
The weak bands at 2206, and 2196-2192 $\mathrm{cm}^{-1}$ are assigned to $\mathrm{CO}$ adsorbed on $\mathrm{Ni}^{2+}$ ions [5]. These bands have different relative intensities in 10 and $14 \%$ loaded samples. This can be considered as an evidence for different positions of these ions in the structure of zeolite.

The band at $2172 \mathrm{~cm}^{-1}$, visible in the spectrum of Ni14/H-USY sample (Figure 3), is less distinctive for Ni10/H-USY and seems absent for $\mathrm{H}$-USY. As soon as its intensity correlates with that of the $3490 \mathrm{~cm}^{-1}$ band and is accompanied by the weak perturbation of the band at $3570 \mathrm{~cm}^{-1}$, it could be tentatively assigned to $\mathrm{CO}$ interaction with sodalite cage $\mathrm{OH}$ groups. Such possibility can be somehow stimulated by nickel ions, which, according to [16], can be bound to sodalite cage oxygen atoms.

$\mathrm{Ni}$ impregnation, apparently, blocks certain part of surface $\mathrm{OH}$ groups, this explains the intensity decrease of the $\mathrm{OH}$ bands in Figure 2. The bands of adsorbed $\mathrm{CO}$ at $2158 \mathrm{~cm}^{-1}$ and below in the spectra of Ni-loaded samples in agreement with earlier studies [17], should be assigned to molecules bound to $\mathrm{Ni}^{+}$ions. Appearance of new bands on desorption is a typical manifestation of lateral interactions between the adsorbed molecules, and sequential observation of three, two and, finally one band should be associated with adsorption of three, two or one molecule at the same site. The method of isotopic dilution or substitution provides more information about the nature of interaction and the arrangement of the interacting molecules.

Isotopic experiments with ${ }^{13} \mathrm{CO}$ provide new detail on the Ni centers in the system. The last $\mathrm{CO}$ band remaining at $2018 \mathrm{~cm}^{-1}$ after desorption even at elevated temperatures in the spectra registered at $77 \mathrm{~K}\left(2014 \mathrm{~cm}^{-1}\right.$ at $\left.300 \mathrm{~K}\right)$ has its ${ }^{13} \mathrm{CO}$ analog at $2069 \mathrm{~cm}^{-1}$. The ratio of frequencies measured with high accuracy from the same spectrum gives a value of isotopic factor 1.0235 . This is a little bit more than the value following from the reduced mass ratio (1.0227) that is typical of Cbonded carbonyl species. We can thus conclude that this is the band of monocarbonyl species bound to $\mathrm{A} \mathrm{Ni}^{+}$ion. The same kind of simple isotopic shift is observed for $\mathrm{CO}$ adsorbed on bridged or silanol hydroxyls groups: the bands at 2180 and $2158 \mathrm{~cm}^{-1}$ shift to 2131 and $2109 \mathrm{~cm}^{-1}$, respectively, that corresponds in both cases almost exactly to the factor of 1.0227 .

After removal the most of $\mathrm{H}$-bonded $\mathrm{CO}$ and before the appearance of the bands of dicarbonyls a pair of bands can be seen in the spectrum of adsorbed ${ }^{12} \mathrm{CO}$ at 2124 and $2114 \mathrm{~cm}^{-1}$. One more band of the same compound can be clearly seen at $2158.0 \mathrm{~cm}^{-1}$ in the difference spectrum after subtracting the spectrum with the superimposing band of $\mathrm{CO}$ adsorbed on silanol groups. Corresponding bands of adsorbed ${ }^{13} \mathrm{CO}$ were found at $2108.5,2075$ and $2066.5 \mathrm{~cm}^{-1}$. This species should be unequivocally attributed to $\mathrm{Ni}^{+}\left({ }^{13} \mathrm{CO}\right)_{3}$. Spectra of isotopic mixtures were rather complicated, but after subtracting the spectra of adsorbed ${ }^{12} \mathrm{CO}$ and ${ }^{13} \mathrm{CO}$ in the region of interest there remained six main bands, which were assigned to $\mathrm{Ni}^{+}\left({ }^{12} \mathrm{CO}\right)_{2}\left({ }^{13} \mathrm{CO}\right)$ and $\mathrm{Ni}^{+}\left({ }^{12} \mathrm{CO}\right)\left({ }^{13} \mathrm{CO}\right)_{2}$, as proposed below in Table 1. The spectra of tricarbonyls are close to those obtained earlier by Hadjiivanov et al for Ni-ZSM-5 $[5,17,18]$, who observed the bands of $\mathrm{Ni}^{+}\left({ }^{12} \mathrm{CO}\right)_{3}$ at 2156, 2124, $2109 \mathrm{~cm}^{-1}$, and those of $\mathrm{Ni}^{+}\left({ }^{13} \mathrm{CO}\right)_{3}$ at $2110,2078,2061 \mathrm{~cm}^{-1}$. Very close frequencies of mono-, diand tricarbonyl species were reported also for Ni-BEA [20] zeolites.

If we turn to the next stage of $\mathrm{CO}$ desorption, when two bands are seen in the spectrum of pure isotopomers, the shifts and relative intensities of individual bands are better seen in simplified decomposition to gaussian curves shown in Figure 8. 


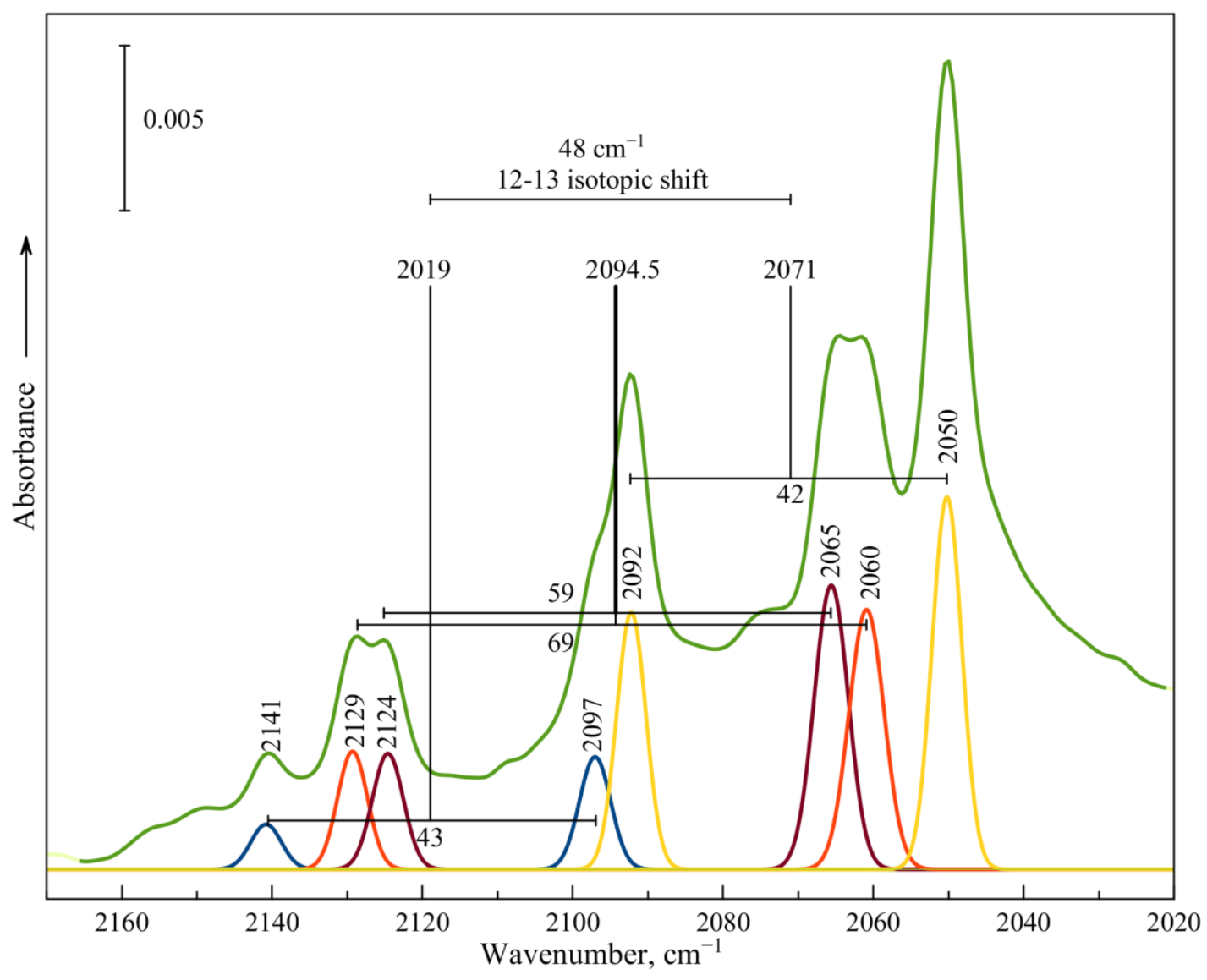

Figure 8. FTIR spectrum of $72 \%{ }^{13} \mathrm{CO}+28 \%{ }^{12} \mathrm{CO}$ mixture adsorbed on Ni10/H-USY after pumping for $15 \mathrm{~min}$ in the cooled cell with subsequent addition of 0.1 Torr of He at $77 \mathrm{~K}$; and the result of its deconvolution.

The pair of bands of adsorbed ${ }^{12} \mathrm{CO}$ at 2141 and $2097 \mathrm{~cm}^{-1}$, preceding the appearance of monocarbonyl, and their ${ }^{13} \mathrm{CO}$ analogues at 2091.5 and $2050 \mathrm{~cm}^{-1}$ are certainly due to dicarbonyl complexes $\mathrm{Ni}^{+}\left({ }^{12} \mathrm{CO}\right)_{2}$ and $\mathrm{Ni}^{+}\left({ }^{13} \mathrm{CO}\right)_{2}$. Again, we can state that isotopic ratios, 1.0237 and 1.0229 are close to the theoretically expected value. Not evident is the assignment of two pairs of bands observed simultaneously with the bands of the above dicarbonyl species on adsorption of ${ }^{12} \mathrm{CO}+{ }^{13} \mathrm{CO}$ isotopic mixtures at 2129, 2125 and 2065, $2061 \mathrm{~cm}^{-1}$. According to the conditions of the experiment, these bands should be associated with the dicarbonyls of mixed isotopic composition $\mathrm{Ni}^{+}\left({ }^{12} \mathrm{CO}\right)\left({ }^{13} \mathrm{CO}\right)$. To explain the band positions we have to take into account that the splitting between the two bands of $\mathrm{Ni}^{+}\left({ }^{12} \mathrm{CO}\right)_{2}$ caused by a strong dipole coupling between the two molecules is $44 \mathrm{~cm}^{-1}$, almost as great as the isotopic shift (about $48 \mathrm{~cm}^{-1}$ ). This means that the resonance should take place between the vibrations of molecules of different isotopic compositions, leading to the increase of the isotopic shift up to the observed values of $2129-2061=68 \mathrm{~cm}^{-1}$. Besides the usual isotopic shift of $48 \mathrm{~cm}^{-1}$, the latter value includes the contribution of resonance coupling equal in this case to $\mathrm{ca} 20 \mathrm{~cm}^{-1}$.

Another problem is to explain the appearance of four bands instead of two. The presence of extra bands can be the result of site heterogeneity. One pair of bands, say, the high-frequency components at 2129 and $2065 \mathrm{~cm}^{-1}$, can be assigned to dicarbonyls on one kind of sites, while another - those at lower wavenumbers of 2125 and $2061 \mathrm{~cm}^{-1}$ - on other sites, somehow different. But in this case the presence of different sites should be reflected in the spectra of 
monocarbonyls or dicarbonyls of pure isotopic composition. But the bands of the latter species are sharp, without any splitting or even broadening. Thus, the sites are identical, and the dissimilarity between two molecules bound to the same $\mathrm{Ni}^{+}$site originates from their way of linkage to it if they form a binary complex. The two molecules are not equivalent, and if one, e.g. ${ }^{12} \mathrm{CO}$ is in a position corresponding to slightly higher absorption frequency, another, ${ }^{13} \mathrm{CO}$ in our case, should be in such a position, that its frequency will be additionally lowered, and the distance between the bands, which includes the isotopic shift and the contribution from the resonance coupling will be additionally increased. Otherwise, the position of the ${ }^{13} \mathrm{CO}$ band will be moved upwards, then the frequency of the partner ${ }^{12} \mathrm{CO}$ molecule should be lowered, and the total splitting will be smaller. The latter case corresponds to the pair of bands at 2125 and 2065 with the splitting of $c a 60 \mathrm{~cm}^{-1}$. For isotopically pure dicarbonyls with two identical molecules, such as $\mathrm{Ni}^{+}\left({ }^{12} \mathrm{CO}\right)_{2}$, it is of no importance, which of them occupies what position, and there is no splitting. We have not detected any splitting of the bands of tricarbonyls of the mixed isotopic composition, although one cannot be sure that there is no additional broadening because of a great number of superimposed bands.

One can state that we deal with an interesting case of linkage isomerism of adsorbed CO molecules, when two dicarbonyl structures can be distinguished spectroscopically if they consist of two different isotopomers. Unlike usual isomerism when $\mathrm{CO}$ molecule can be bound to the cation either via carbon or oxygen, and the two structures not only vary in frequencies, but have different adsorption energies [21], in our case both have equal energies, but their dissimilarity is clearly manifested in their spectra. We cannot say yet firmly, what is the origin of their difference. It can be somehow connected with their orientation with respect to the environment. For instance, two CO molecule approach the $\mathrm{Ni}^{+}$site from two different sides, such as from the hexagonal prism or from the supercage. However, the difference is observed only when the second molecule is added to one already adsorbed. For monocarbonyls the molecules are bound to $\mathrm{Ni}^{+}$sites in one similar way, and do not manifest any sign of alternative adsorption, since the $2118 \mathrm{~cm}^{-1}$ band is narrow, symmetric and has not any hint on splitting or broadening neither at $77 \mathrm{~K}$, nor at ambient temperature.

Table 1 Positions of band maxima in the spectra of $\mathrm{CO}$ adsorbed on Ni-USY zeolite*

\begin{tabular}{|c|l|l|l|l|l|}
\hline Type & $\begin{array}{l}\text { Chemical } \\
\text { structure }\end{array}$ & \multicolumn{2}{|l|}{ Band wavenumber, $\mathrm{cm}^{-1}$} & $\begin{array}{l}\text { Center of } \\
\text { mass }\end{array}$ \\
\hline \multirow{4}{*}{ Monocarbonyls } & $\mathrm{Ni}^{+}\left({ }^{12} \mathrm{CO}\right)$ & 2118 & & & \\
\cline { 2 - 6 } & $\mathrm{Ni}^{+}\left({ }^{13} \mathrm{CO}\right)$ & 2069 & & & \\
\hline \multirow{5}{*}{ Dicarbonyls } & $\mathrm{Ni}^{+}\left({ }^{12} \mathrm{CO}\right)_{2}$ & 2141 & 2097 & & 2119 \\
\cline { 2 - 6 } & $\mathrm{Ni}^{+}\left({ }^{12} \mathrm{CO}\right)\left({ }^{13} \mathrm{CO}\right)$ & 2129. & 2061 & & 2095 \\
\cline { 2 - 6 } & 2125.0 & 2065. & & 2095 \\
\cline { 2 - 6 } & $\mathrm{Ni}^{+}\left({ }^{13} \mathrm{CO}\right)_{2}$ & 2091 & 2050 & & 2130.5 \\
\hline \multirow{5}{*}{ Tricarbonyls } & $\mathrm{Ni}^{+}\left({ }^{12} \mathrm{CO}\right)_{3}$ & 2158 & 2124 & 2114 & 2132 \\
\cline { 2 - 6 } & $\mathrm{Ni}^{+}\left({ }^{12} \mathrm{CO}\right)_{2}\left({ }^{13} \mathrm{CO}\right)$ & 2149 & 2120 & $2089 ?$ & 2100 \\
\cline { 2 - 6 } & $\mathrm{Ni}^{+}\left({ }^{12} \mathrm{CO}\right)\left({ }^{13} \mathrm{CO}\right)_{2}$ & 2138 & 2086 & $2076 ?$ & 2083 \\
\cline { 2 - 6 } & $\mathrm{Ni}^{+}\left({ }^{13} \mathrm{CO}\right)_{3}$ & 2108 & 2075 & 2066 & \\
\hline
\end{tabular}

* the frequency values observed at $77 \mathrm{~K}$.

The method of isotopic dilution enables us to distinguish static and dynamic (resonance) interaction between the adsorbed molecules. In our case the splitting between the two bands of dicarbonyls is a manifestation of strong resonance dynamic interaction. The static interaction is comparatively strong and repulsive. In fact, to remove the first molecule from tricarbonyl pumping 
of frozen cell is enough. Next molecule can be desorbed by evacuation at room temperature, but the last CO molecule resist even pumping at $373 \mathrm{~K}$. Repulsive static interaction manifests itself in the shift of the band of adsorbed molecules from the position determined by adsorption interaction in the direction to that of a free molecule, diminishing the shift caused by adsorption. For $\mathrm{ZnO}$ the frequency of coordinately adsorbed molecules, which increases from 2143 up to $2192 \mathrm{~cm}^{-1}$ due to adsorption, is lowered because of static interaction up to $2162 \mathrm{~cm}^{-1}$ [22]. In our case the mean value of two bands of dicarbonyl $\left(2119 \mathrm{~cm}^{-1}\right)$ almost coincides with the position of monocarbonyl $\left(2018 \mathrm{~cm}^{-1}\right)$, while the addition of the third molecule moves the mean frequency value to $2132 \mathrm{~cm}^{-1}$ (see Table 1). The shift upwards reflects the weakening of backdonation with the increasing number of ligands, the kind of static shift in our case. The initial frequency shift from the value of a free molecule $\left(2143 \mathrm{~cm}^{-1}\right)$ diminishes from 25 up to $11 \mathrm{~cm}^{-1}$, for the third molecule, but not for the second one, although the energy of adsorption is much lower, than for the first. This could mean that two molecules in dicarbonyl do not feel repulsion between each other, but adsorption of the second weakens the bond of both with the cation. For oxides static interaction is enhanced by the solid due to the effect of relaxation induced by adsorption [23], i.e. the changing of interatomic distances in the superficial layer. The absence of such effect on adsorption of the second molecule can be understood as an evidence for adsorption of two molecules at the same cation, but not on two neighboring atoms in a cluster or on an oxocation such as $(\mathrm{Ni}-\mathrm{O}-\mathrm{Ni})^{+2}$.

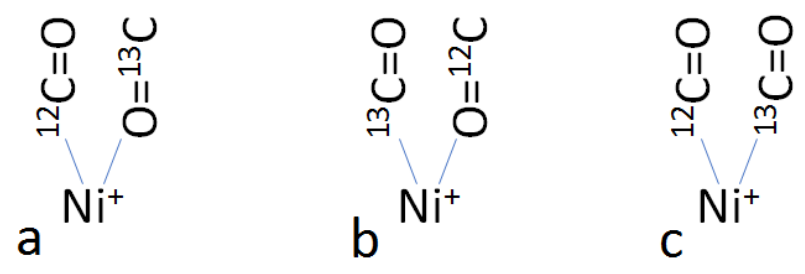

Figure 9. Possible $\mathrm{Ni}^{+}$dicarbonyl configurations.

The properties of dicarbonyl species can be illustrated by the above scheme (Figure 9), where two molecules are coordinated in different way to the same $\mathrm{Ni}^{+}$ion, and thus, structures $a$ and $b$ have different frequencies. The dipoles of the two molecules are oriented in opposite directions and there is no direct repulsion of dipoles. Back donation of d-electrons of $\mathrm{Ni}$ to $\mathrm{CO}$ molecules makes them close to NO, which has a tendency to form dimers. If the interaction between the molecules becomes attractive, there is no reason for the mean frequency to increase with respect to monocarbonyl, and the formation of dicarbonyl of two C-bonded molecules (Figure 9 structure $c$ ) turns to be energetically less favorable. The possibility to form such a structure with non-equivalent molecules crucially depends on the properties of the metal, then it is not by chance that it was found only for nickel which has unique properties as a catalyst for the Sabatier reaction. Of course, this is only a hypothesis, and to establish the real structure of the dicarbonyl we need quantum chemical modeling and extra experimental date. However, the finding of such isotopic isomerism itself seems to be important and worth further investigation.

\section{Conclusions}

The study of $\mathrm{CO}$ adsorption on reduced $\mathrm{Ni}$-containing USY zeolites with $\mathrm{Si} / \mathrm{Al}=30$ has been carried out by means of FTIR spectroscopy at variable temperatures. The bands of bridged $\mathrm{OH}$ groups of both initial H-USY and Ni-loaded samples are unusually narrow. The same can be said about the band of perturbed hydroxyls and adsorbed CO. Apparently, this is due to the high Si/Al ratio. The spectra of 
$\mathrm{CO}$ adsorbed on Ni-containing zeolites, also with extremely sharp bands, change dramatically with the coverage. Three bands at 2152, 2124 and $2114 \mathrm{~cm}^{-1}$, which disappear after evacuation of the cell, cooled with liquid nitrogen, should be assigned to tricarbonyls $\mathrm{Ni}^{+}(\mathrm{CO})_{3}$. The remaining dicarbonyls, characterized by two distinct bands at 2141 and $2097 \mathrm{~cm}^{-1}$, can be eliminated by evacuation at $300 \mathrm{~K}$, leaving monocarbonyl, which has a sharp band at $2118 \mathrm{~cm}^{-1}$ (at $77 \mathrm{~K}$ ).

The surface nickel dicarbonyl species exhibit an interesting phenomenon that can be called isotopic isomerism, when two CO molecules occupy not equivalent positions, and the spectrum of isotopically mixed species has two pairs of bands, slightly differing from each other. As an explanation illustrating such possibility, a structure of two molecules is proposed, where one CO molecule is bound to $\mathrm{Ni}^{+}$cation via carbon, another- via oxygen atom.

\section{Acknowledgement.}

The work was supported by RFBR and CITMA, grant No. 18-53-34004. R.B. is grateful to the Ministère des Affaires Etrangères Français for the Metchnikov scholarship.

\section{References:}

[1] X. Su, J. Xu, B. Liang, H. Duan, B. Hou, Y. Huang, J. Energy Chem. 25 (2016) 553-565.

[2] I. Graça, L. V. González, M.C. Bacariza, A. Fernandes, C. Henriques, J.M. Lopes, M.F. Ribeiro, Appl. Catal. B Environ. 147 (2014) 101-110.

[3] F. Thibault-Starzyk, F. Maugé, in: J.V. M.Che (Ed.), Charact. Solid Mater. Heterog. Catal. From Struct. to Surf. React., Wiley, 2012, pp. 1-48.

[4] G. Busca, Phys. Chem. Chem. Phys. 1 (1999) 723-736.

[5] K.I. Hadjiivanov, G.N. Vayssilov, Adv. Catal. 47 (2002) 307-511.

[6] S. Bordiga, C. Lamberti, F. Bonino, A. Travert, F. Thibault-Starzyk, Chem. Soc. Rev. 44 (2015) 7262-7341.

[7] E. Dooryhee, C.R.A. Catlow, J.W. Couves, P.J. Maddox, J.M. Thomas, G.N. Greaves, A.T. Steel, R.P. Townsend, J. Phys. Chem. 95 (1991) 4514-4521.

[8] P. Gallezot, Y. Ben Taarit, B. Imelik, J. Catal. 26 (1972) 481-483.

[9] T.A. Egerton, J.C. Vickerman, J. Chem. Soc. Faraday Trans. 1 Phys. Chem. Condens. Phases 261 (1973) 39-49.

[10] C.O. Arean, O. Manoilova, A. Tsyganenko, G.T. Palomino, M. Mentruit, F. Geobaldo, E. Garrone, Eur.J.Inorg.Chem. (2001) 1739-1743.

[11] C.W. Hu, J. Yao, H.Q. Yang, Y. Chen, A.M. Tian, J. Catal. 166 (1997) 1-7.

[12] O. Cairon, T. Chevreau, J.-C. Lavalley, J. Chem. Soc. Faraday Trans. 94 (1998) 3039-3047.

[13] A.A. Tsyganenko, E. V. Kondratieva, V.S. Yanko, P.Y. Storozhev, J. Mater. Chem. 16 (2006) 2358.

[14] P.Y. Storozhev, C. Otero Areán, E. Garrone, P. Ugliengo, V.. Ermoshin, A.. Tsyganenko, Chem. Phys. Lett. 374 (2003) 439-445.

[15] G. Busca, Microporous Mesoporous Mater. 254 (2017) 3-16.

[16] P. Gallezot, Y.Ben Taarit, B. Imelik, J. Phys. Chem. 77 (1973) 2556-2560.

[17] A.I. Serykh, M.D. Amiridis, J. Phys. Chem. C 111 (2007) 17020-17024.

[18] K.I. Hadjiivanov, H. Knözinger, M.Y. Mihaylov, J. Phys. Chem. B 106 (2002) 2618-2624.

[19] H.A. Aleksandrov, V.R. Zdravkova, M.Y. Mihaylov, P.S. Petkov, G.N. Vayssilov, K.I. Hadjiivanov, J. Phys. Chem. C 116 (2012) 22823-22831. 
[20] A. Penkova, S. Dzwigaj, W.R. Kefirov, K. Hadjiivanov, M. Che, J. Phys. Chem. C 111 (2007) 8623-8631.

[21] C.O. Areán, G.T. Palomino, A.A. Tsyganenko, E. Garrone, Int. J. Mol. Sci. 3 (2002) 764-776.

[22] L.A. Denisenko, A.A. Tsyganenko, V.N. Filimonov, React. Kinet. Catal. Lett. 25 (1984) 23-26.

[23] A.A. Tsyganenko, S.M. Zverev, React. Kinet. Catal. Lett. 36 (1988) 269-274. 
Click here to download high resolution image

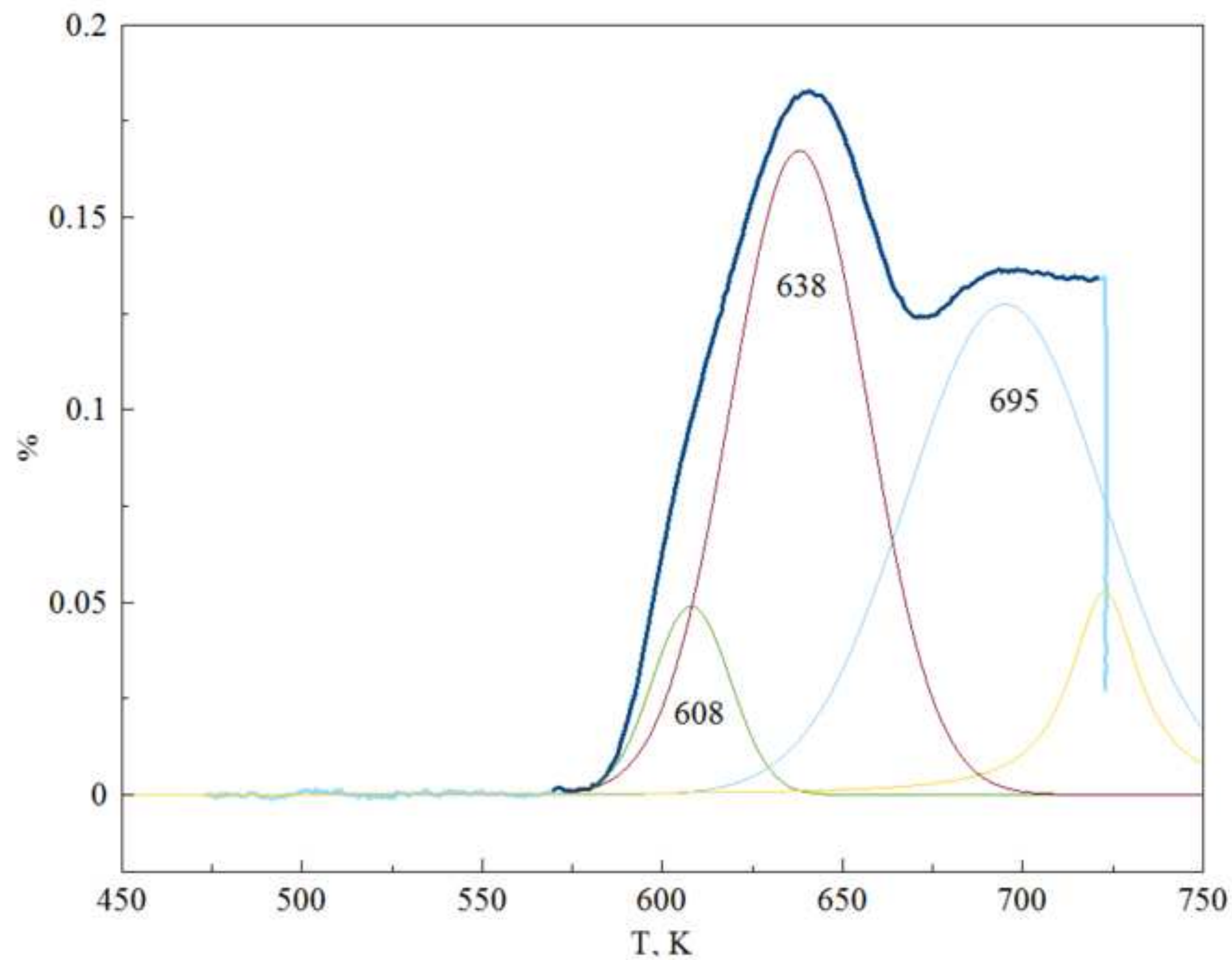




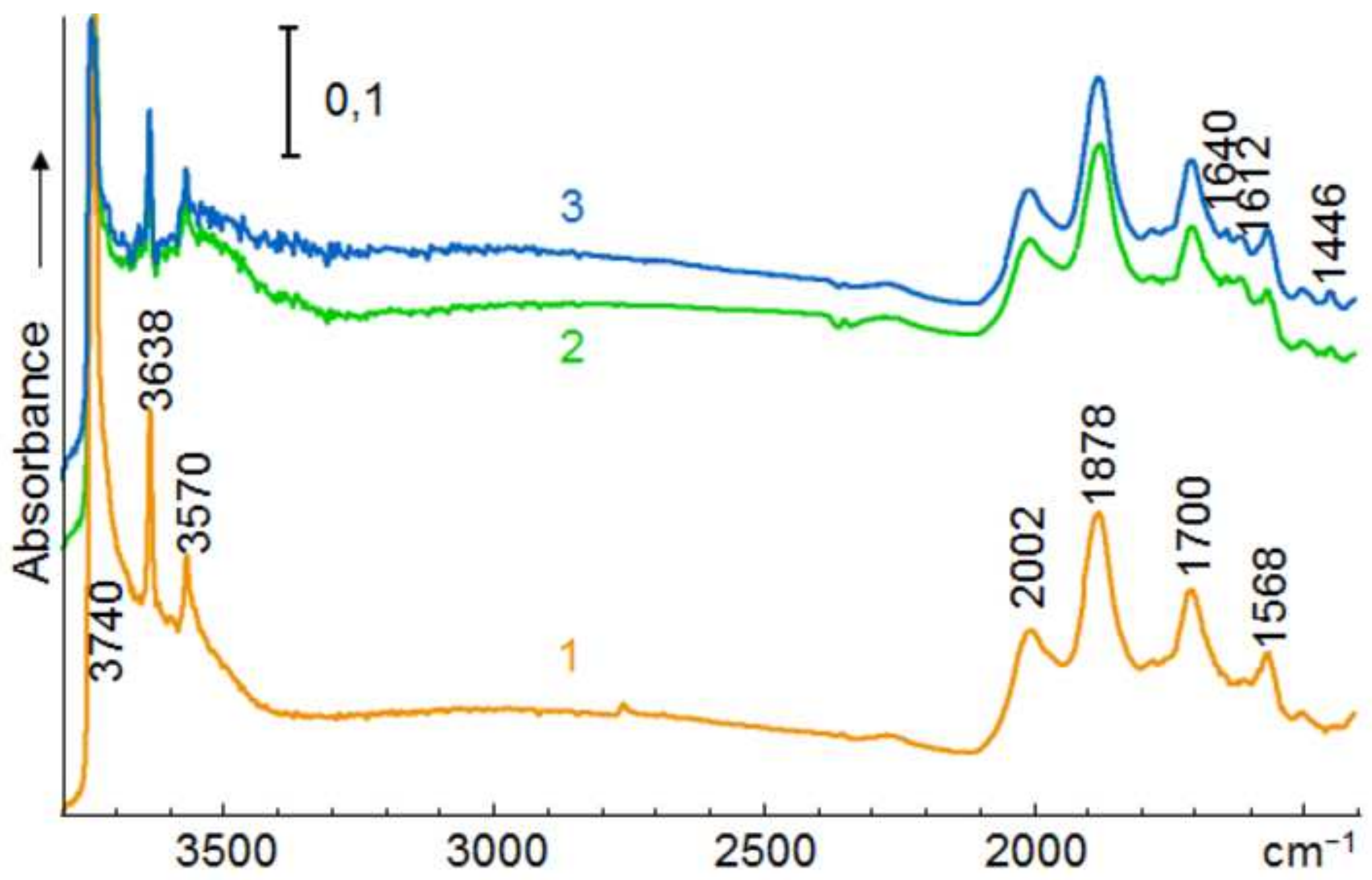




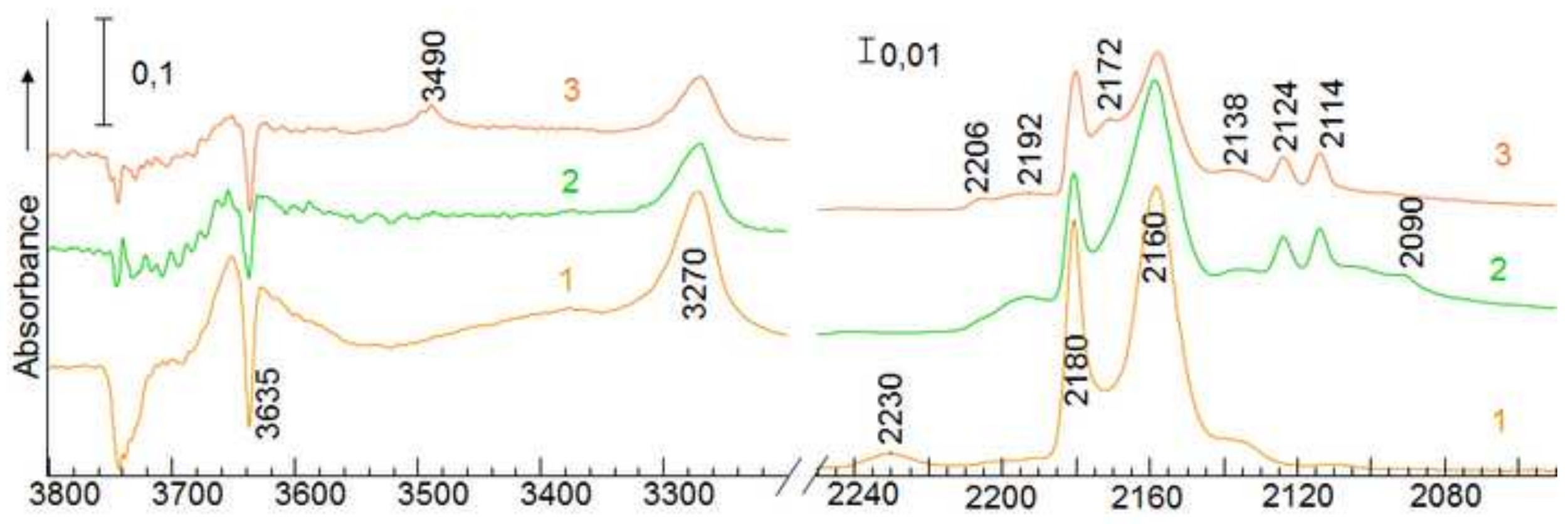




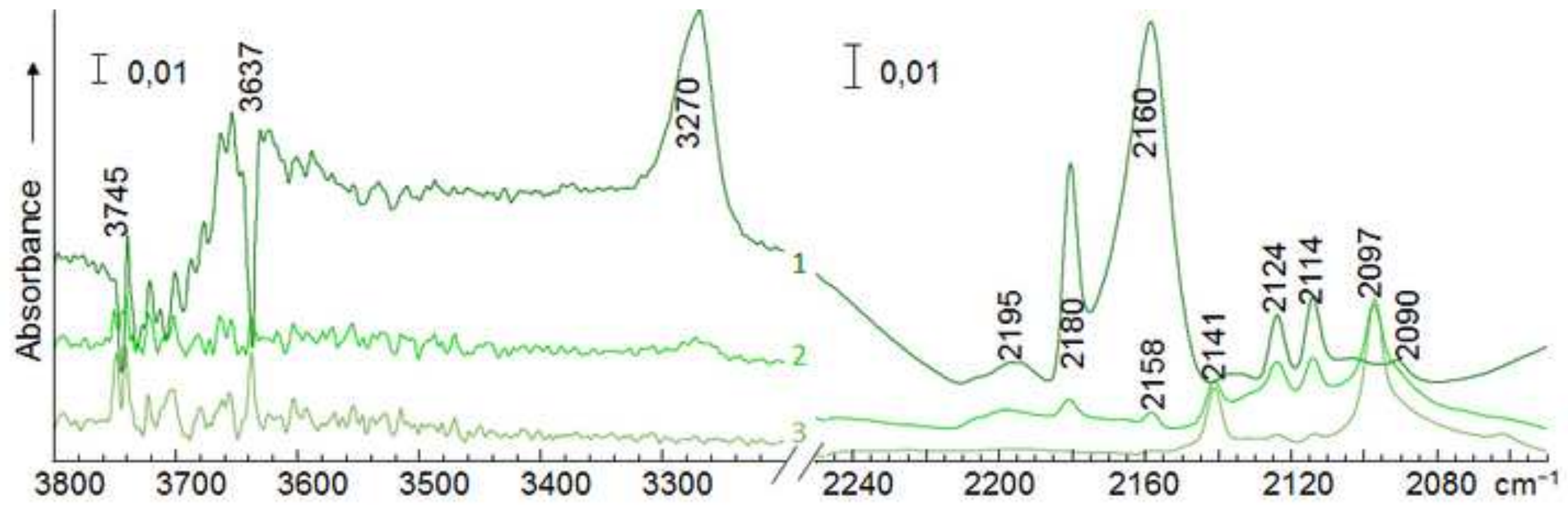




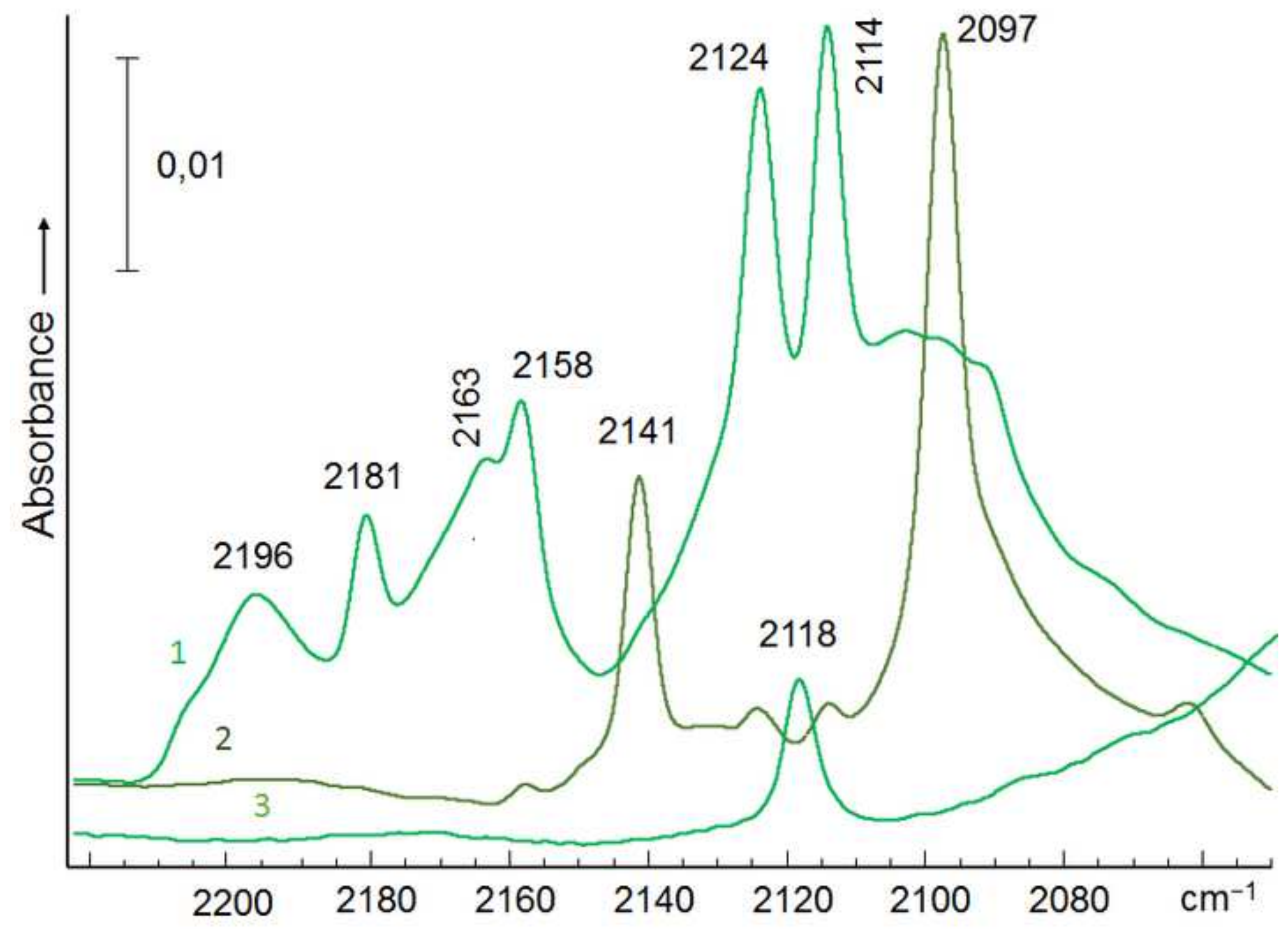




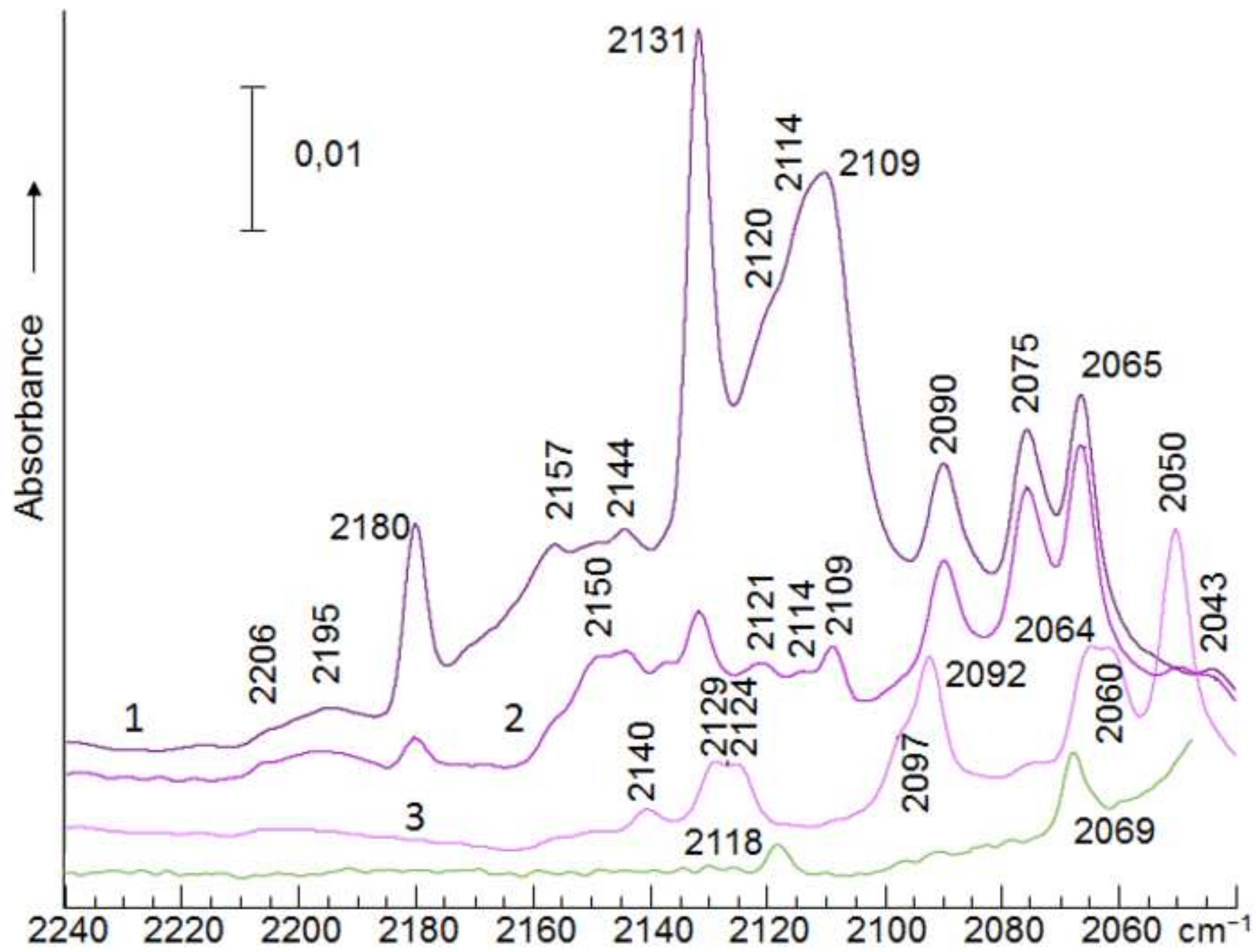




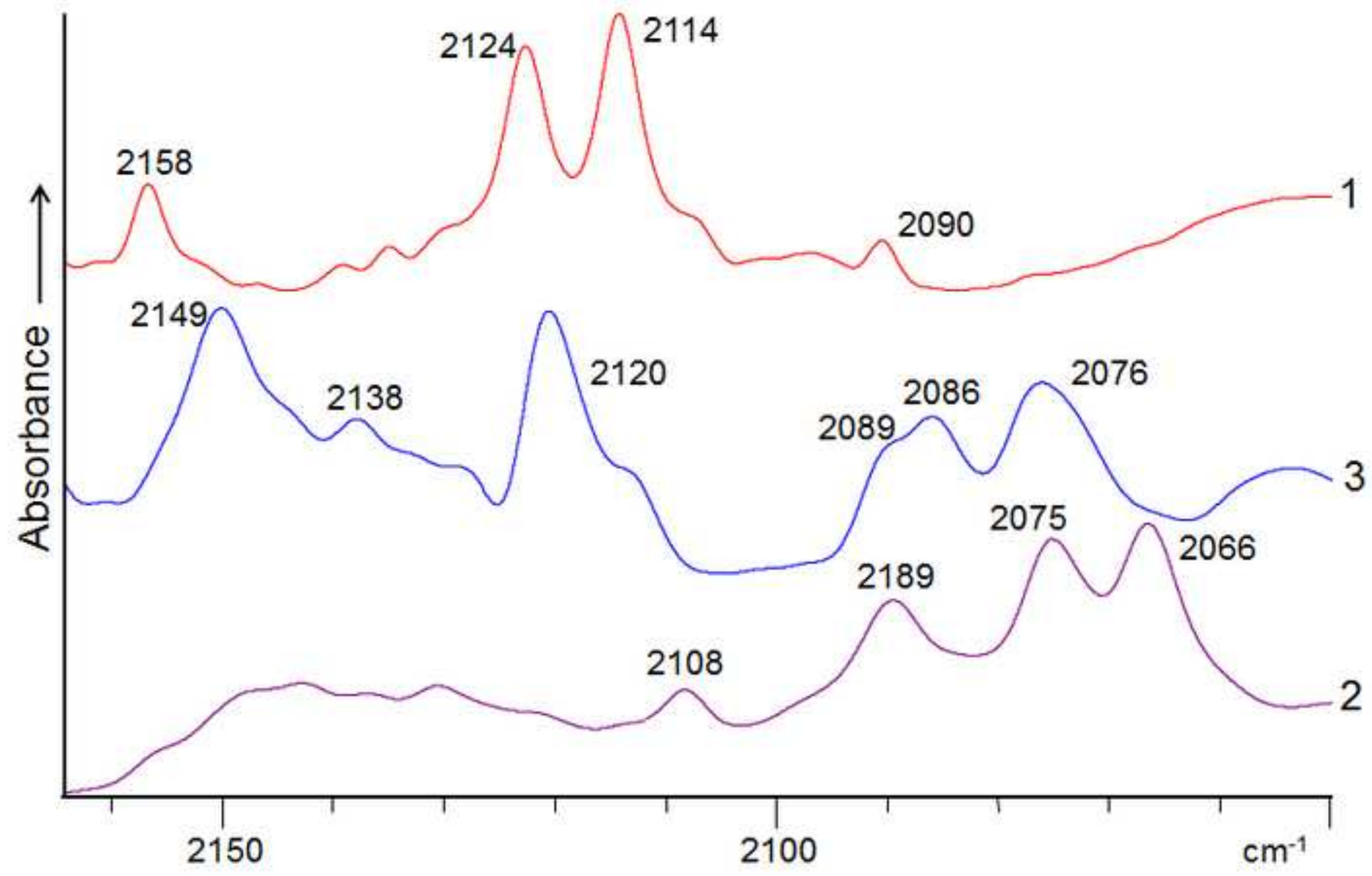




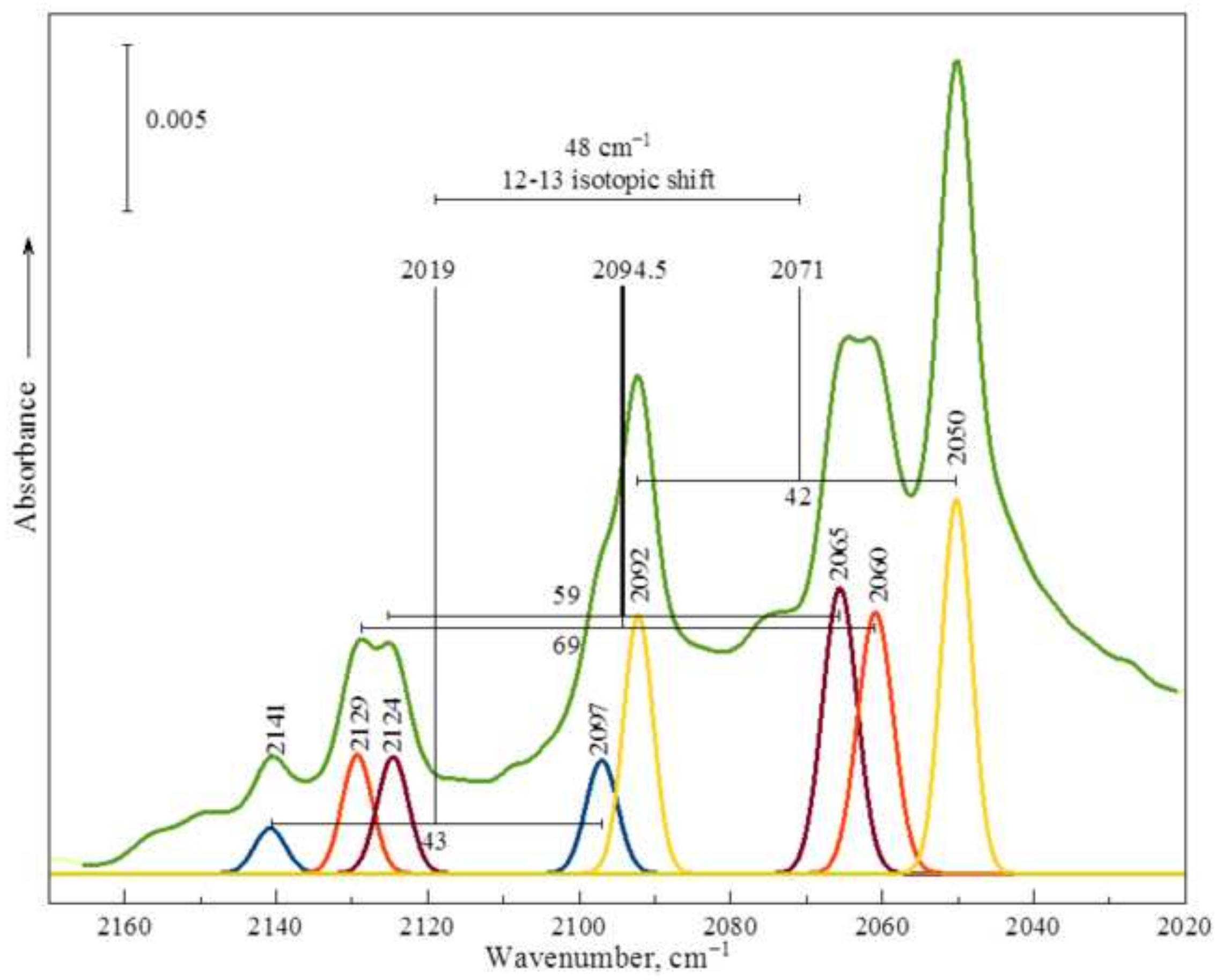



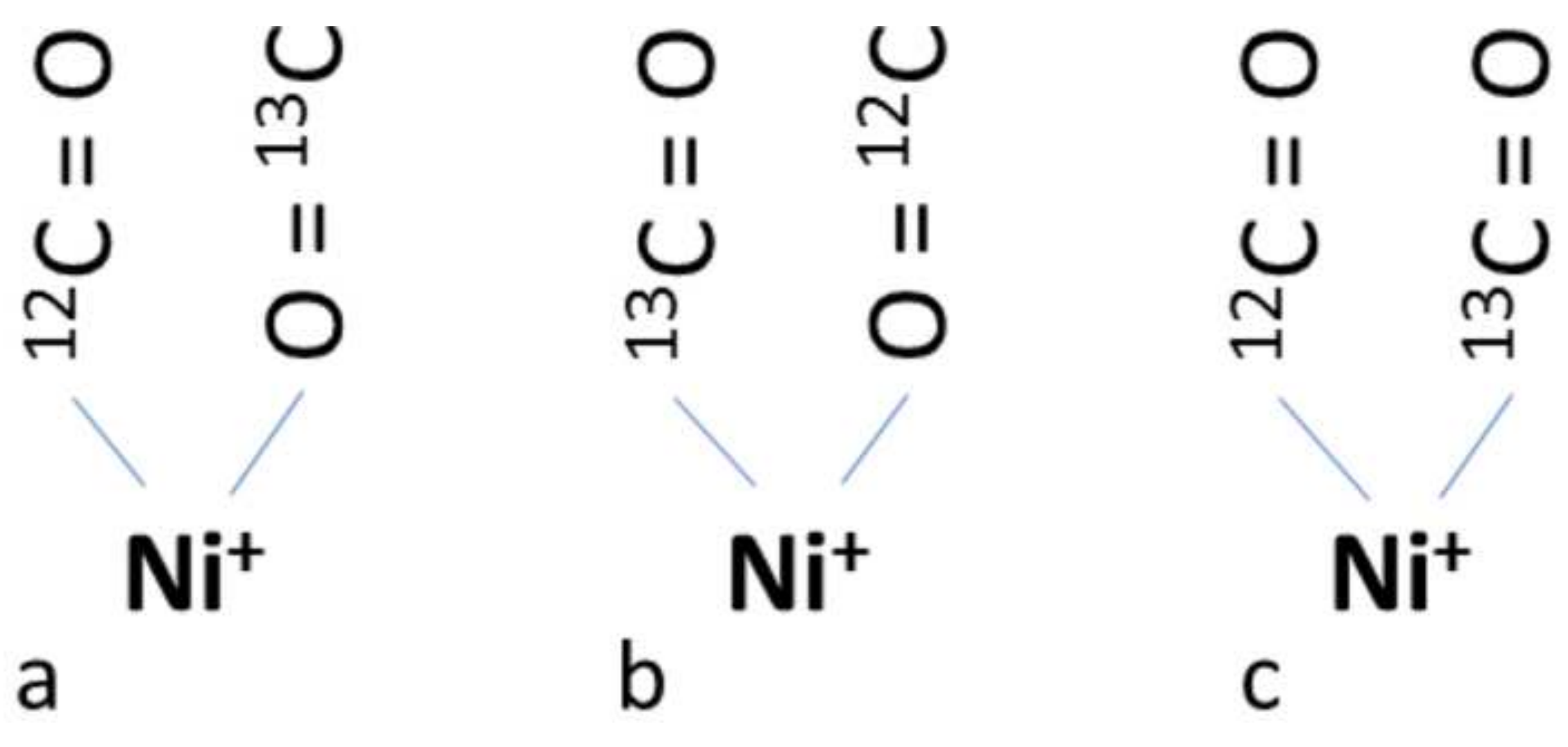

a

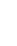
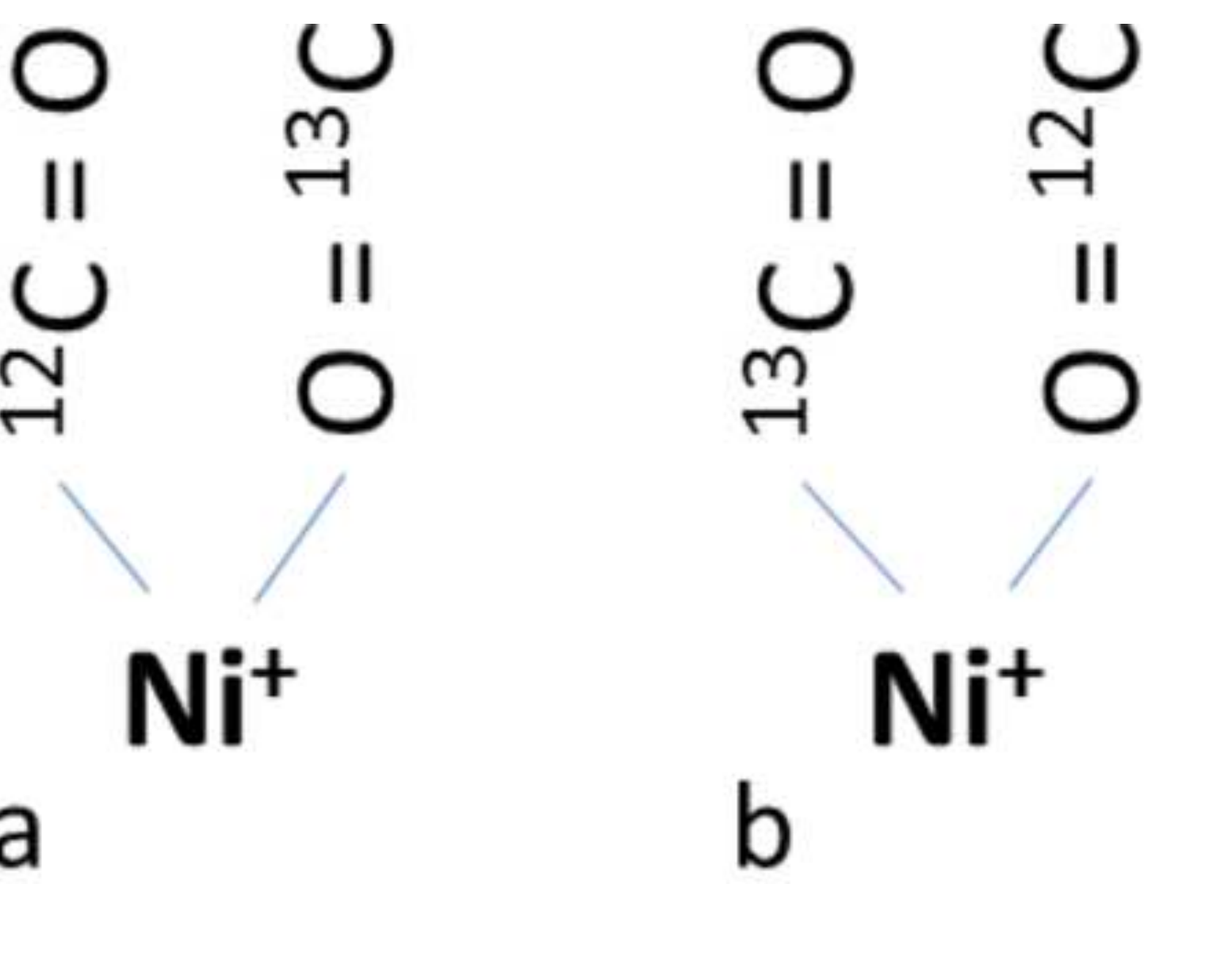